\title{
Ship collision damage assessment and validation with experiments and numerical simulations
}

\author{
Zhang, Shengming; Villavicencio, R.; Zhu, L.; Pedersen, P. Terndrup
}

Published in:

Marine Structures

Link to article, DOI:

10.1016/j.marstruc.2018.09.005

Publication date:

2019

Document Version

Peer reviewed version

Link back to DTU Orbit

Citation (APA):

Zhang, S., Villavicencio, R., Zhu, L., \& Pedersen, P. T. (2019). Ship collision damage assessment and validation with experiments and numerical simulations. Marine Structures, 63, 239 - 256.

https://doi.org/10.1016/j.marstruc.2018.09.005

\section{General rights}

Copyright and moral rights for the publications made accessible in the public portal are retained by the authors and/or other copyright owners and it is a condition of accessing publications that users recognise and abide by the legal requirements associated with these rights.

- Users may download and print one copy of any publication from the public portal for the purpose of private study or research.

- You may not further distribute the material or use it for any profit-making activity or commercial gain

- You may freely distribute the URL identifying the publication in the public portal 


\title{
For Marine Structures
}

\section{Ship Collision Damage Assessment and Validation with Experiments and Numerical Simulations}

\author{
Shengming Zhang, ${ }^{\mathrm{a}, 1}$, R. Villavicencio ${ }^{\mathrm{a}, 2}$, L. Zhu ${ }^{\mathrm{b}, *}, 3$, P. Terndrup Pedersen ${ }^{\mathrm{b}, \mathrm{c}, 4}$ \\ ${ }^{a}$ Global Technology Centre, Lloyd’s Register EMEA, Southampton SO16 7QF, UK \\ ${ }^{\mathrm{b}}$ Wuhan University of Technology, Wuhan, China \\ c Department of Mechanical Engineering, Technical University of Denmark, DK-2800 Lyngby, Denmark
}

*Corresponding author: ZL79111@hotmail.com

\begin{abstract}
Closed-form expressions to estimate the energy absorption and damage extent for severe ship collision damages were initially developed in 1999 [1, 2], and further validated with experimental data in 2016 [3]. To gain further confidence for applications within design using the proposed analytical procedure, it is evident that more detailed and comprehensive comparisons and validations with experiments and numerical simulations are necessary. The purpose of the present paper is to use the analytical approach and finite element analyses to study in depth model-scale and full-scale collision tests so that to further quantify key calculation parameters and to verify the capability and accuracy of the proposed analytical method. In total 18 experimental tests and one full-scale collision accident are evaluated. The 18 experimental energy absorptionpenetration and collision force-penetration curves, and the associated finite element simulations, are compared with results obtained from the analytical calculations. It can be concluded that the analytical method gives consistently good agreement with all experiments analysed here. Finally, an application of the analytical method is demonstrated by an example where speed restrictions are determined in a port to avoid LNG cargo leakage in an event of an LNG carrier being struck by another ship.
\end{abstract}

Keywords: ship collision, damage assessment, energy absorption, collision force, analytical solution, finite element analysis, experimental result, collision risk management.

\footnotetext{
${ }^{1}$ Member ISSC2009\&2015 Committee Ultimate Strength, ISSC2012 Committee Fatigue and Fracture

${ }^{2}$ Member ISSC2018 Committee Fatigue and Fracture

${ }^{3}$ Member ISSC1998 Committee Collisions and Grounding, ISSC2018 Committee Design Principles

${ }^{4}$ Chairman ISSC1988, Member ISSC2006 Committee Collisions and Grounding
} 


\section{Introduction}

A ship-ship collision is a major hazard for ship operations. It can result in loss of human lives and severe environmental damages. This has leaded the maritime community to increase the efforts to mitigate the probability and consequences of ship collision accidents. To develop effective rules and procedures to reduce the risk associated with ship-ship collision events, three steps are required [4]:

(1) A procedure to evaluate the probability of ship collision events in specific sea traffic conditions.

(2) Given a ship-ship collision, then a procedure is needed to estimate the energy which will be released for structural damage of the involved ship structures (External Dynamics).

(3) Knowing the energy to be absorbed by structural damage, a method is then required to estimate the structural damage extent of the ship structures (Internal Mechanics).

The second step (on external dynamics) has been discussed and addressed by the authors in [5], where an analytical method to estimate the energy released for crushing of structures was validated with results of 58 model tests and two full-scale experiments. For the third step (internal mechanics), various research works have been published, for example [1, 6-8]. The determination of the damage extent in ship collision analysis plays a key role in collision assessments [9].

Minorsky [10] proposed an empirical approach to deal with the structural damage back in 1959 and 26 collision cases of full-scale ship accidents were analysed and developed the empirical formula $E=47.2 R+$ 32.7 which relates the absorbed energy $E$ (in $M J$ ) to the destroyed material volume $R$ (in $\mathrm{m}^{3}$ ). Though the limitations of this approach are recognised, this empirical formula has been widely used by the industry for ship collision and grounding analyses.

Recently, in 2016, Zhang and Pedersen [3] further examined their simplified analytical method, first presented in 1999 [1, 2], to estimate the damage extent during collision accidents. The method is based on the relationship between the absorbed energy and the volume of the damaged material, and takes into account the structural arrangements, material properties and damage modes. A large number of experimental tests were compared with calculated results obtained by the analytical method [3]. Good agreement was achieved. However, it was not the strongest validation because the energy predictions were only verified at a given penetration, e.g. usually at the final damage penetration for each collision experiment. Therefore, it is important to verify the energy response as well as the collision force behaviour during the entire impact event, e.g. at any damage penetration, so that to reflect the full picture of the collision assessment and to validate the robustness of the method.

Non-linear finite element analysis (FEA) has become a popular tool in recent years for ship collision studies [11-15]. In these numerical analyses, one of the key issues is to establish a suitable failure criterion as it has significant effects on the results. The rupture criteria are commonly determined through calibration with uniaxial tensile tests where a relation between the element size and the rupture strain can be established. Although significant efforts have been made in this respect, the scatter of the results between finite element analyses using some of the suggested criteria is still quite large, as demonstrated by Storheim et al. [14].

In fact, the determination of the material rupture strain is critical for both finite element and analytical methods. This parameter can be adjusted to get a good agreement with a particular set of experimental results, but on the other hand, the same adjustment cannot guarantee good agreement with other experiments, and consequently, it is one of the biggest challenges for ship collision damage assessments. The friction coefficient between the indenter and laterally impacted structure also influences the response, though its effect is 'less critical' than the effect of the rupture strain. This paper will address this issue in a consistent way.

The present paper reassess the effectiveness of the analytical method [1, 2] by comparing its predictions with 18 collision experiments of double hull structures and one full-scale collision accident. The absorbed energy and impact forces are evaluated throughout the entire impact process where the rupture strain and friction coefficient are treated in a consistent manner in the analytical calculations. Finite element simulations for three experimental models are carried out to observe the contribution of friction and the deformation and damage patterns in the collision response. 
It can be concluded that the analytical method predicts the entire impact response with sufficient accuracy for all collision cases evaluated here when a common criterion is consistently used to determine the key parameters. Thus, the method is recommended for collision appraisals as that required in [9].

\section{Damaged material volume method}

The analysis and observation of actual ship collision damages reveal that there are two main energy absorption mechanisms involved in the internal mechanics of ship collisions: (a) plastic tension deformation, such as indentation and rupture of the shell plating during the collision, and (b) folding and crushing damage mode, such as crushing and folding of webs, decks and bottoms.

Zhang [1] and Pedersen and Zhang [2] developed formulas for the relationship between the absorbed energy and the damaged material volume for the two energy absorption modes:

(1). Energy absorption by the plastic tension damage mode can be calculated from:

$$
E_{1}=0.77 \varepsilon_{f} \sigma_{0} R_{1}
$$

where $E_{1}$ is the absorbed energy, $\sigma_{0}$ is the flow stress of the material, $\varepsilon_{\mathrm{f}}$ is the rupture strain of the material, and $R_{1}$ is the material volume of the damaged/ruptured structural members in tension mode. Before rupture of the shell plating, $\varepsilon_{\mathrm{f}}$ is replaced with $\left(x / x_{\mathrm{f}}\right) \varepsilon_{\mathrm{f}}$ where $x$ is the penetration and $x_{\mathrm{f}}$ is the critical penetration when the shell ruptures.

(2). Energy absorption by the crushing and folding damage mode can be determined from:

$$
E_{2}=3.50\left(\frac{t}{b}\right)^{0.67} \sigma_{0} R_{2}
$$

where $t$ is the thickness of the crushed plate, $b$ is the width of the plate in the crushed cross-section, and $R_{2}$ is the material volume of the crushed structural members.

(3) The total absorbed energy can be obtained from the summation of the energy absorbed by each damaged structural member:

$$
E_{\text {total }}=\sum E_{1}+\sum E_{2}
$$

(4). The material properties are important parameters for energy absorption collision analyses. These parameters are commonly obtained from standard uniaxial tensile tests and include: yield stress $\sigma_{\mathrm{y}}$, ultimate tensile stress $\sigma_{\mathrm{u}}$, and elongation at break $\varepsilon_{\mathrm{f}}$ (referred here as rupture strain). In the present paper, the flow stress of the materials is taken as the average of the yield stress and the ultimate tensile stress:

$$
\sigma_{0}=0.5\left(\sigma_{y}+\sigma_{u}\right)
$$

By studying materials data from the shipbuilding industry, it is found that the rupture strain is strongly influenced by the ultimate tensile stress of the materials. In general, with the increase of the ultimate tensile stress, the rupture strain decreases. The rupture strain used in the present analytical calculations is obtained from uniaxial tensile tests, if it is available. On the other hand, material databases have been consulted to define reliable data when the tensile test information is not available.

(5). It is usually assumed that the striking bow is rigid in ship-ship collision analysis, and thus all collision energy is absorbed by the struck ship. In such cases, the structural damage can be approximately determined by assuming that the damage to the struck ship is confined around the rigid striking bow. This assumption is well supported by the observations from actual ship-ship collision damages. Fig. 1 illustrates structural members damaged by a bulbous bow. 

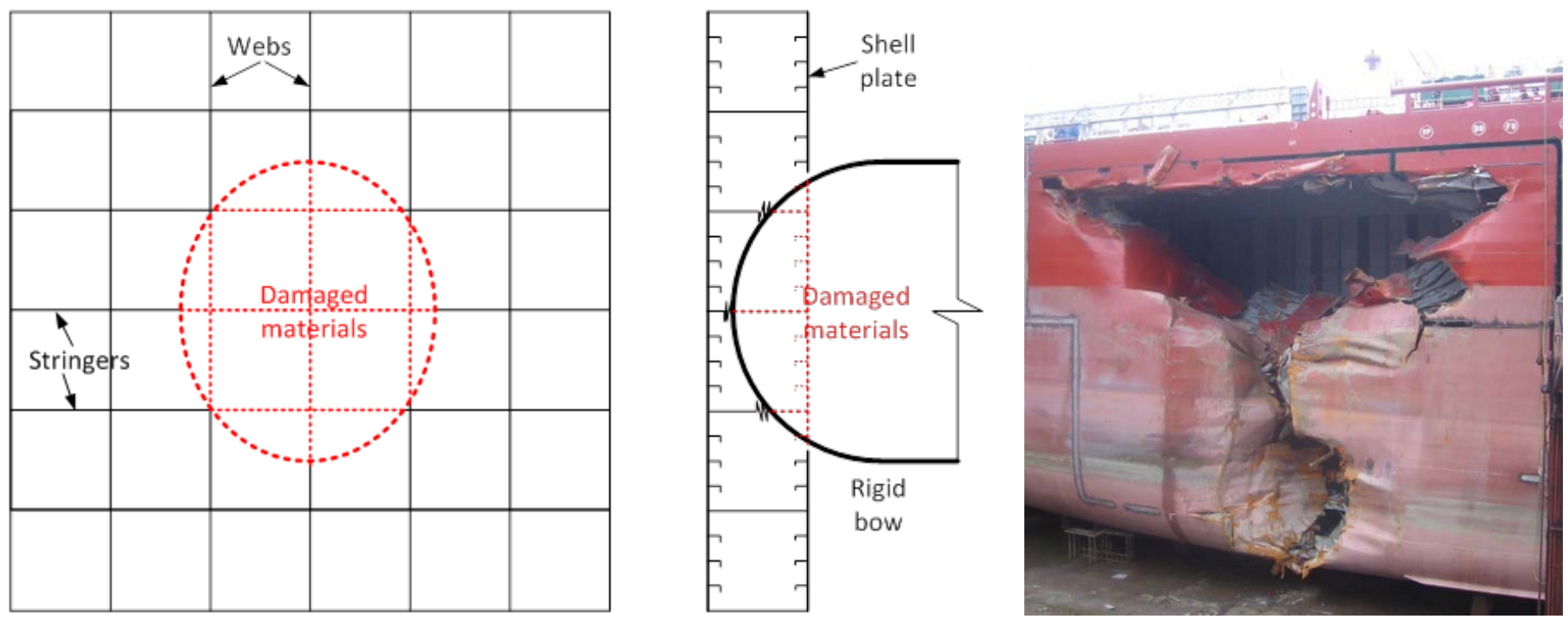

Figure 1: Illustration of damaged materials by a bulbous bow (shell plates ruptured, webs crushed).

(6). While the friction between a rigid bow and the damaged structures results in an additional absorbed energy, friction effects were ignored in the previous analyses carried out with the analytical method [1-3]. Karlsson et al. [16] evaluated and measured the friction coefficient between steels, and found that this coefficient can be set at $\mu=0.23$; this magnitude has been frequently used in ship collision simulations.

However, it is believed that the contribution from friction is not significant in ship collisions, and hence some finite element analyses have adopted this assumption. Here, finite element simulations are performed to further investigate the contribution of the friction on the energy absorption (see Section 3). The simulations use a friction coefficient $\mu=0.23$ and the FEA results reveal that its effect is negligible when the penetration is small, and that it increases with the penetration. It is also concluded that friction contributes only about $10 \%$ to the total dissipated energy at relatively large penetrations. Considering this, the analytical calculations assume that the contribution of friction is about $10 \%$, except for particular cases mentioned in the comparisons with the experiments (Section 4) where friction is negligible. This is implemented by first calculating the absorbed energy with Eqs. (1) to (3), and then increasing the energy $E_{\text {total }}$ by $11.5 \%$; it is adopted for simplicity and to minimize the input uncertainties.

(7). For the collision force calculations, it should be pointed out that the collision force-penetration curves are obtained by the derivative of the energy-penetration curves, i.e. $F=\mathrm{d} E / \mathrm{d} x$ ( $F=$ force, $E=$ energy, $x=$ penetration). In this way, the obtained collision force represents the average value within each analyzed step and the peak force in the experiments caused by buckling is not reflected in the calculation. The calculated forcepenetration curves reflect the overall trend of the collision resistance.

\section{Finite element simulations}

In this section, finite element simulations of the three double hull collision experiments reported by Arita and Aoki [17] are presented. The purpose is to obtain the energy-penetration and force-penetration curves and to estimate the contribution of the friction during the impact response. The numerical analysis uses the material failure criteria proposed by Liu et al. [15]. It should be mentioned that these experiments were published in Japanese, and to the authors knowledge, numerical simulations of them have not been reported in the open literature. Therefore, these experimental results and simulations can be used as one more set of benchmark data for future analytical and numerical methods for assessing ship collisions.

The computations are carried out using the finite element package LS-DYNA (Version 971) which is appropriate for non-linear explicit dynamic simulations with large deformations [18]. Most numerical 
definitions adopted in the present study follow the simulations reported in [15, 19], which are briefly reviewed next for reference.

The dimensions, scantlings, and material properties of the double hull structures, and the indenter geometry, can be found in Section 4.1. The finite element model of specimen S-II is shown in Fig. 2 (a) for reference. The outer and inner plates and the webs are modelled by four-node shell elements with five-integration points throughout the thickness, defining the Belytschko-Lin-Tsay shell element formulation. The indenter is modelled by four-node shell elements with zero integration points, defining the rigid material 'Mat.020-Rigid' to ensure no deformation. The specimens are fully clamped at the four edges: ends of the outer and inner plates and webs.
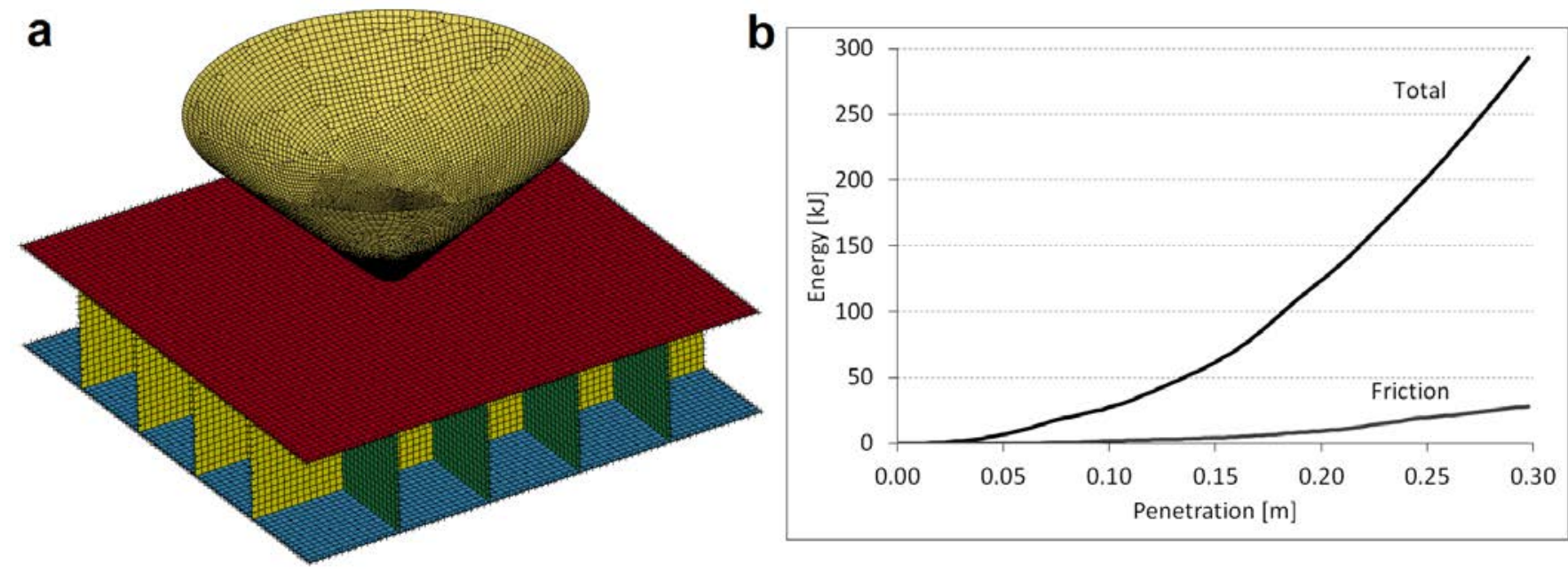

Figure 2: (a) Finite element model of specimen S-II (b) Energy-penetration curve (specimen S-II): total absorbed energy and energy dissipated by friction.

The contact between the indenter and the specimen is defined as 'Contact Automatic Single Surface'. In the LS-DYNA contact card, the static coefficient of friction is set at 0.23 as suggested in [16]. The indenter is subjected to a constant prescribed displacement to enforce the deformation of the specimen.

The true stress-strain of the material is characterised by the power law relation $\sigma_{\mathrm{t}}=K \varepsilon_{\mathrm{t}}{ }^{n}$ where the strength coefficient $K$ and the strain hardening exponent $n$ are determined from equations that require as inputs only the material yield stress $\sigma_{\mathrm{y}}$, and the ultimate tensile strength $\sigma_{\mathrm{u}}$ [15]. Here, $K=650 \mathrm{MPa}$ and $n=0.17$ for the 3.2 mm plates, and $K=670 \mathrm{MPa}$ and $n=0.17$ for the $4.5 \mathrm{~mm}$ plates. This material model is valid for mild and high tensile strength steels (235 $\mathrm{MPa}<\sigma_{\mathrm{y}}<355 \mathrm{MPa}$ ), assumes that the origin of the flow curve is very close to $\varepsilon_{\mathrm{t}}=0.006$ and that the engineering strain at the ultimate tensile strength $\varepsilon_{\mathrm{u}}$ is equal to the strain hardening exponent [15]. The material selected from the library of LS-DYNA is 'Mat.123-Modified Piecewise Linear Plasticity', which allows the definition of a true stress-strain curve as an offset table and failure based on the effective plastic strain.

The critical 'true' failure strain $\varepsilon \mathrm{ft}$ is determined by Eq. (5), where $l_{\mathrm{e}}$ is the length of the finite elements and $t$ is the thickness [15]. This expression can be used to estimate the failure strain of coarsely meshed ship structures (5t to 20t) struck by an indenter with hemispherical shape, so that to simulate a ship-to-ship collision scenario where the bulbous bow penetrates the side shell structure. This 'simple strain-state-independent failure criterion' assumes a constant critical equivalent strain at failure, and accounts for the size of the elements. Eq. (5) is valid for mild and high strength steel materials and was validated against reported experiments of 3 stiffened plates and 6 double-hull structures quasi-statically punched by a conical indenter with hemispherical nose [15].

$$
\varepsilon_{\mathrm{ft}}=0.50-0.01\left(\frac{l_{\mathrm{e}}}{t}\right)
$$


The mesh size selected for the simulations is $20 \mathrm{~mm}$, i.e. $6.25 \mathrm{t}$ for the plates of thickness $3.2 \mathrm{~mm}$ and $4.44 \mathrm{t}$ for the plates of thickness $4.5 \mathrm{~mm}$, resulting in a failure strain of about $\varepsilon_{\mathrm{ft}}=0.45$. Such mesh size is relatively small for assessing a real ship collision event where a recommended mesh would be four or five elements between longitudinals, or about ten times the plate thickness, to find equilibrium between practical engineering application and reasonable results [15].

The results of these simulations will be presented in Section 4.1 together with those of the experiments and analytical calculations. Here, the energy-penetration from the simulation of specimen S-II is presented in Fig. 2 (b) to demonstrate that the contribution of the friction between the indenter and the plates is about $10 \%$ of the total absorbed energy at relative large penetrations. The same tendency was observed for the other two specimens.

\section{Comparisons of analytical results with experiments and numerical simulations}

In this part, eighteen model test collision experiments and one full-scale collision accident are used as benchmark to compare the predictions of the analytical method. Finite element results are also included in the comparisons.

The analytical analysis procedures described in Section 2 are consistently employed for estimating the response of all experiments. Since only the FEA simulation of the three model tests by Arita and Aoki [17] are conducted here, other FEA numerical results used for the comparison are taken from the appropriate literatures.

\subsection{Three model tests by Arita and Aoki [17]}

Arita and Aoki [17] performed collision tests on three models of double hull structures penetrated by a rigid conical indenter of radius $R=80 \mathrm{~mm}$. The structural arrangement of the models is shown in Fig. 3 and the dimensions are given in Table 1.

The material properties are also summarised in Table 1 . The yield stress of the mild steel material is obtained from [17], but information of the ultimate tensile strength and the rupture strain was not clear. The magnitudes of these unknown properties are obtained from material data from the shipbuilding industry.

The comparison of the absorbed energy-penetration and force-penetration curves between analytical results, experimental results and FE simulations is presented in Figs. 4 to 6. The finite element results are based on the model and definitions in Section 3. It is seen from the comparison that the analytical calculations as well as the FE simulations agree well with the experimental results. Additional discussions on the results will be provided in Section 5.

Table 1: Dimensions and material properties of the three model tests of Arita and Aoki [17]

\begin{tabular}{cccccccc}
\hline ID & Model & Webs spacing $(\mathrm{mm})$ & Depth $(\mathrm{mm})$ & $\begin{array}{c}\text { Plates and webs } \\
\text { thickness }(\mathrm{mm})\end{array}$ & $\sigma_{\mathrm{y}}(\mathrm{MPa})$ & $\sigma_{\mathrm{u}}(\mathrm{MPa})$ & $\varepsilon_{\mathrm{f}}(-)$ \\
\hline 1 & & & & 3.2 & 284.5 & 440.0 & 0.35 \\
2 & S-I & 200 & 300 & 4.5 & 294.3 & 447.0 \\
3 & S-II & 280 & 300 & 4.5 & 294.3 & 447.0 & 0.34 \\
\hline
\end{tabular}




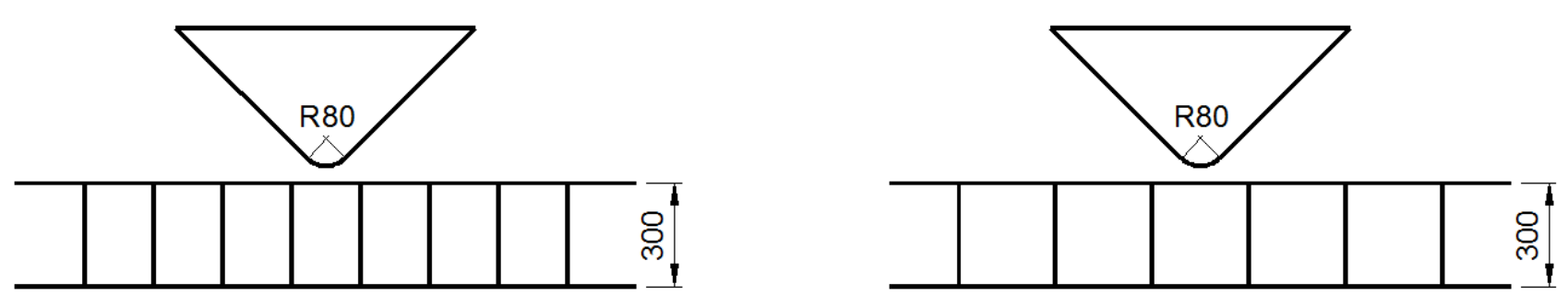

Experimental Support

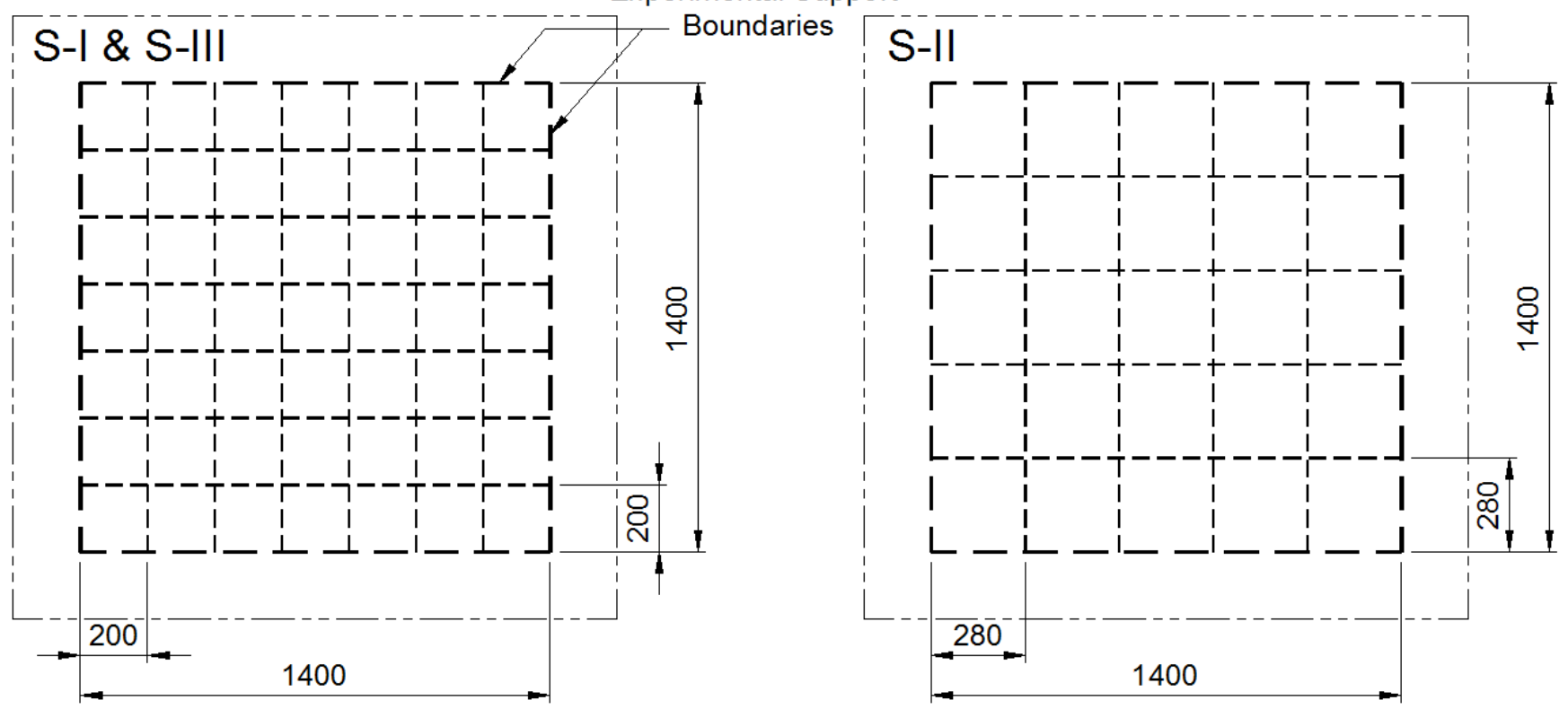

Figure 3: Illustration of Arita and Aoki [17] model tests.
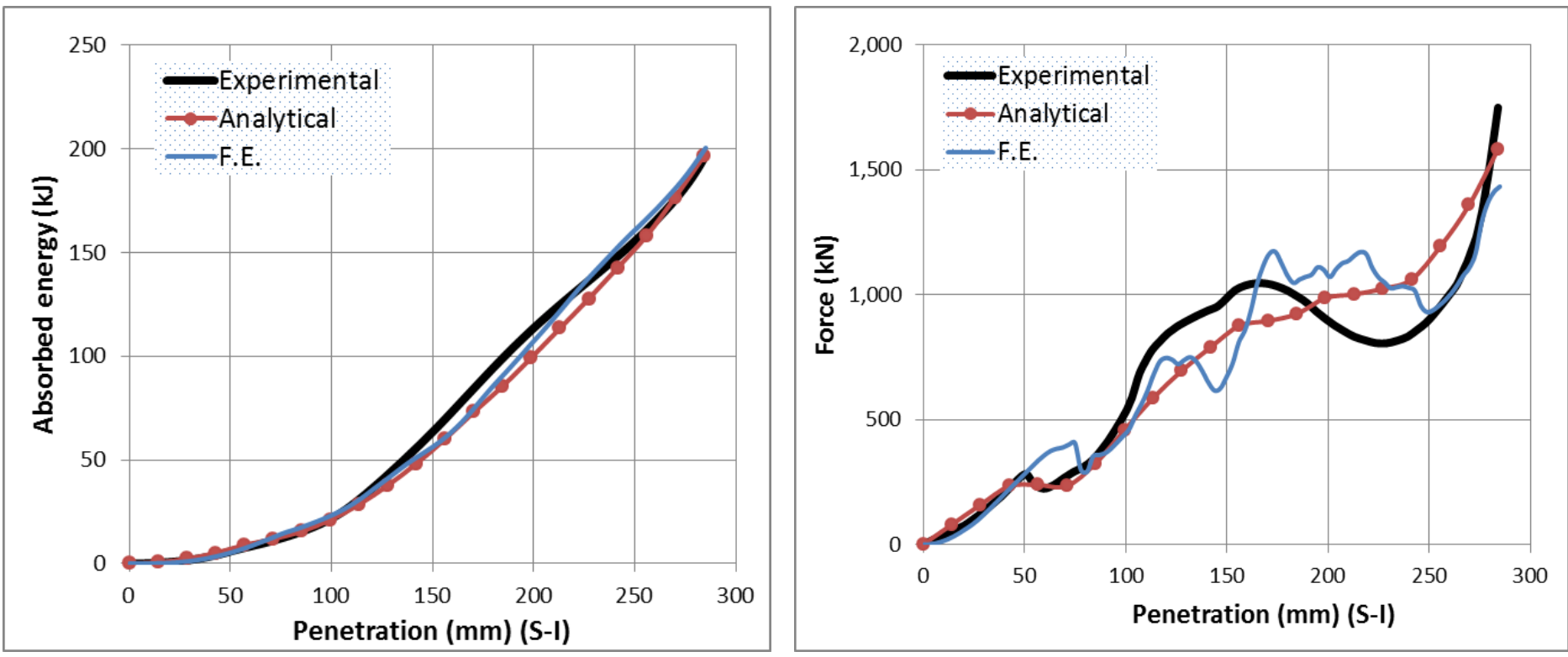

Figure 4: Energy-penetration and force-penetration curves: Model S-I 

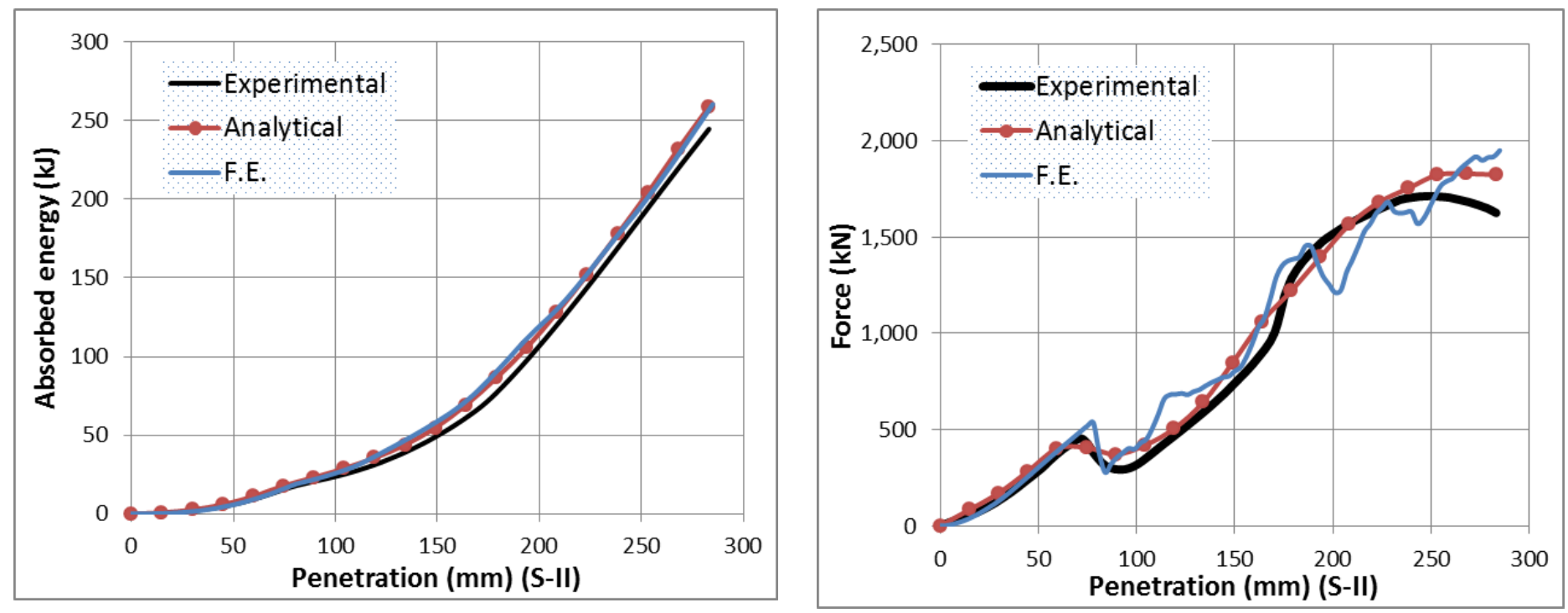

Figure 5: Energy-penetration and force-penetration curves: Model S-II
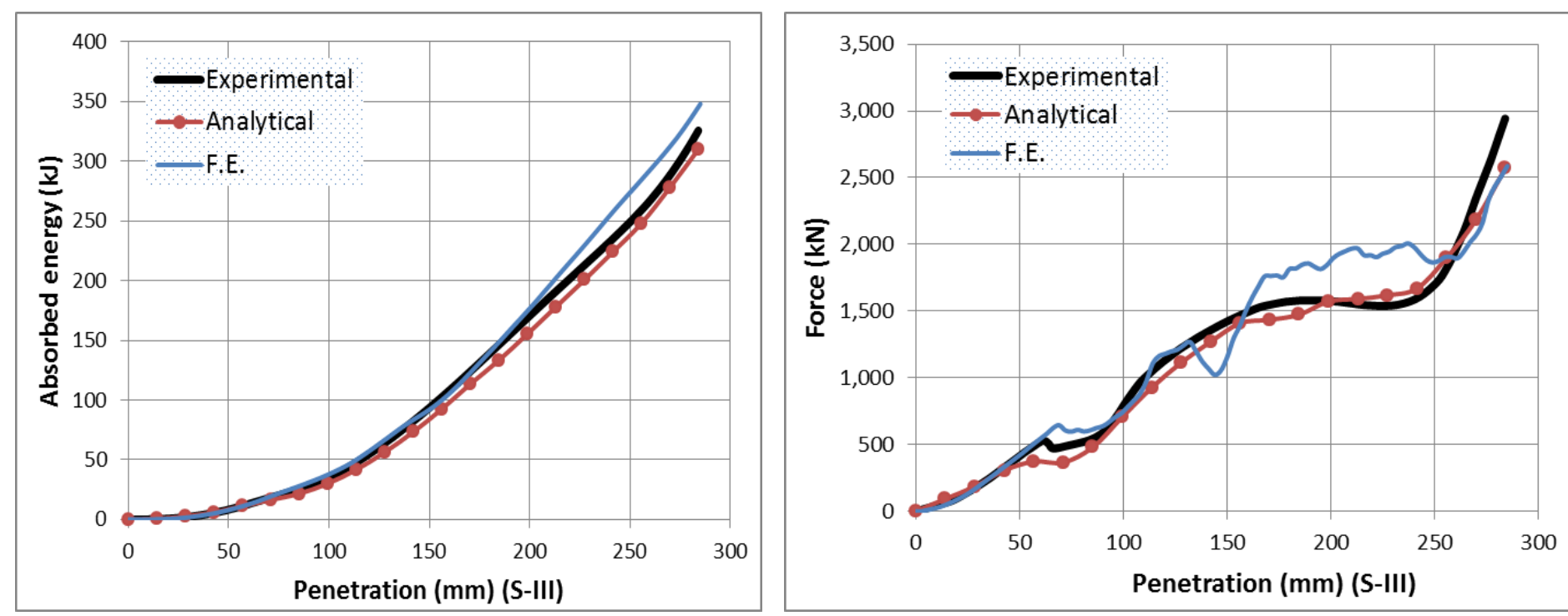

Figure 6: Energy-penetration and force-penetration curves: Model S-III

\subsection{Four model tests by Paik et al. [7]}

Paik et al. [7] carried out collision tests on four double hull models penetrated by a rigid conical indenter of radius $R=80 \mathrm{~mm}$. The structural arrangement of a representative model is shown in Fig. 7 (a), while the dimensions of all specimens are given in Table 2. The material properties were obtained from standard uniaxial tensile tests [7] and are also shown in Table 2.

From the experiments it is noticed that the inner hull has suffered small deflections before the indenter gets into contact with it. Therefore, the analysis penetrations are slightly adjusted taking as reference the experimental data so that to reflect this in the analytical calculations. It is also observed that the indenter did not provoke scratches on the platting of the models, or they were very small, and hence the friction effect is negligible, and eventually it is ignored in the analytical calculations as this gives better agreement. The final damage patterns of two of the test models are shown Fig. 7 (b).

The absorbed energy-penetration and force-penetration curves are compared in Figs. 8 to 11 . The finite element results of specimens ST-3-BW and ST-3-OW are taken from Liu et al. [15], where Eq. (5) was used to estimate the failure strain, but the mesh size is $9 t$. Similarly to the results in Section 4.1, the analytical calculations predict the experimental response with sufficient accuracy. 
a

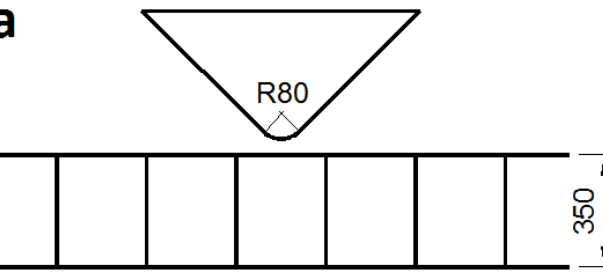

b

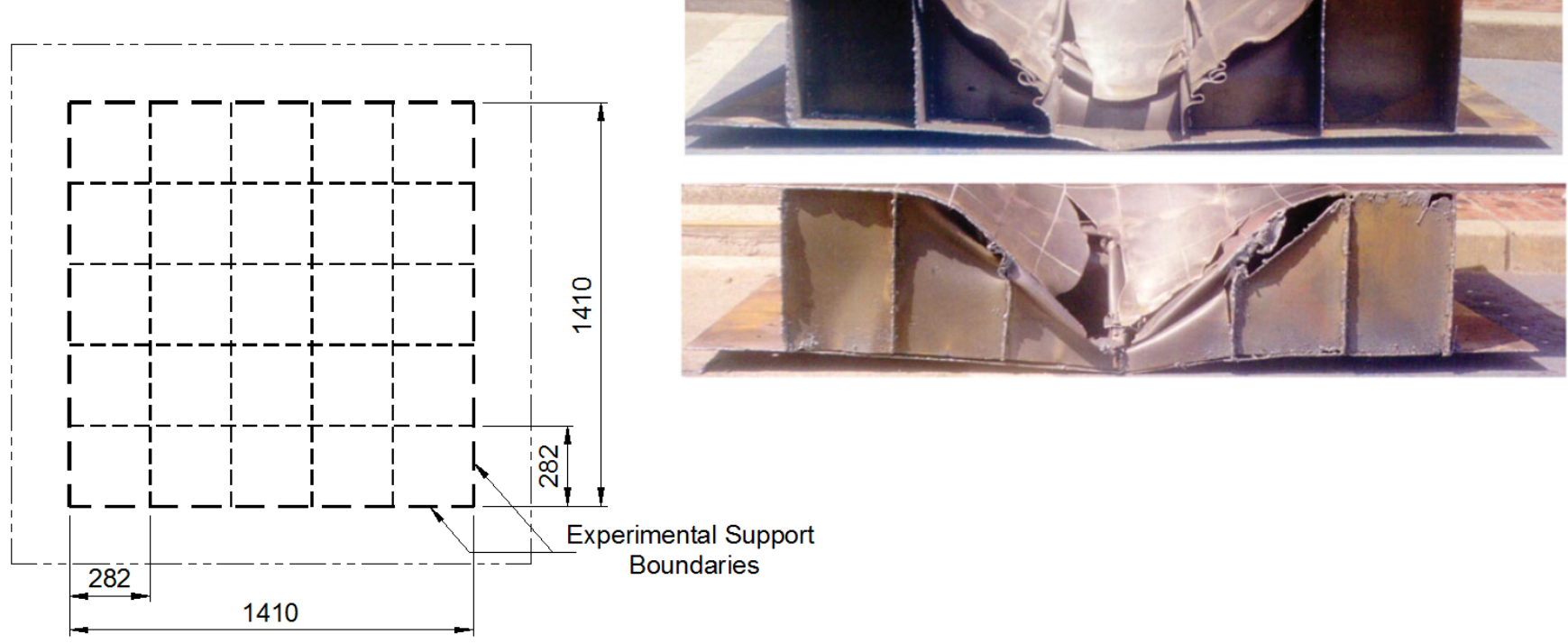

Figure 7: (a) Illustration of the model tests, and (b) Shape of the deformation of test models by Paik et al. [7]

Table 2: Dimensions and material properties of the four model tests of Paik et al. [7]

\begin{tabular}{ccccccccc}
\hline ID & Model & $\begin{array}{c}\text { Web spacing } \\
(\mathrm{mm})\end{array}$ & $\begin{array}{c}\text { Depth } \\
(\mathrm{mm})\end{array}$ & $\begin{array}{c}\text { Plates and webs } \\
\text { thickness }(\mathrm{mm})\end{array}$ & Loading position & $\sigma_{\mathrm{y}}(\mathrm{MPa})$ & $\sigma_{\mathrm{u}}(\mathrm{MPa})$ & $\varepsilon_{\mathrm{f}}(-)$ \\
\hline 4 & ST-3-BW & 282 & 350 & 2.80 & Between webs & 245.3 & 337.8 & 0.46 \\
5 & ST-4-BW & 282 & 350 & 3.95 & Between webs & 319.8 & 412.6 & 0.36 \\
6 & ST-3-OW & 235 & 350 & 2.80 & Web joint & 245.3 & 337.8 & 0.46 \\
7 & ST-4-OW & 235 & 350 & 3.95 & Web joint & 319.8 & 412.6 & 0.36 \\
\hline
\end{tabular}
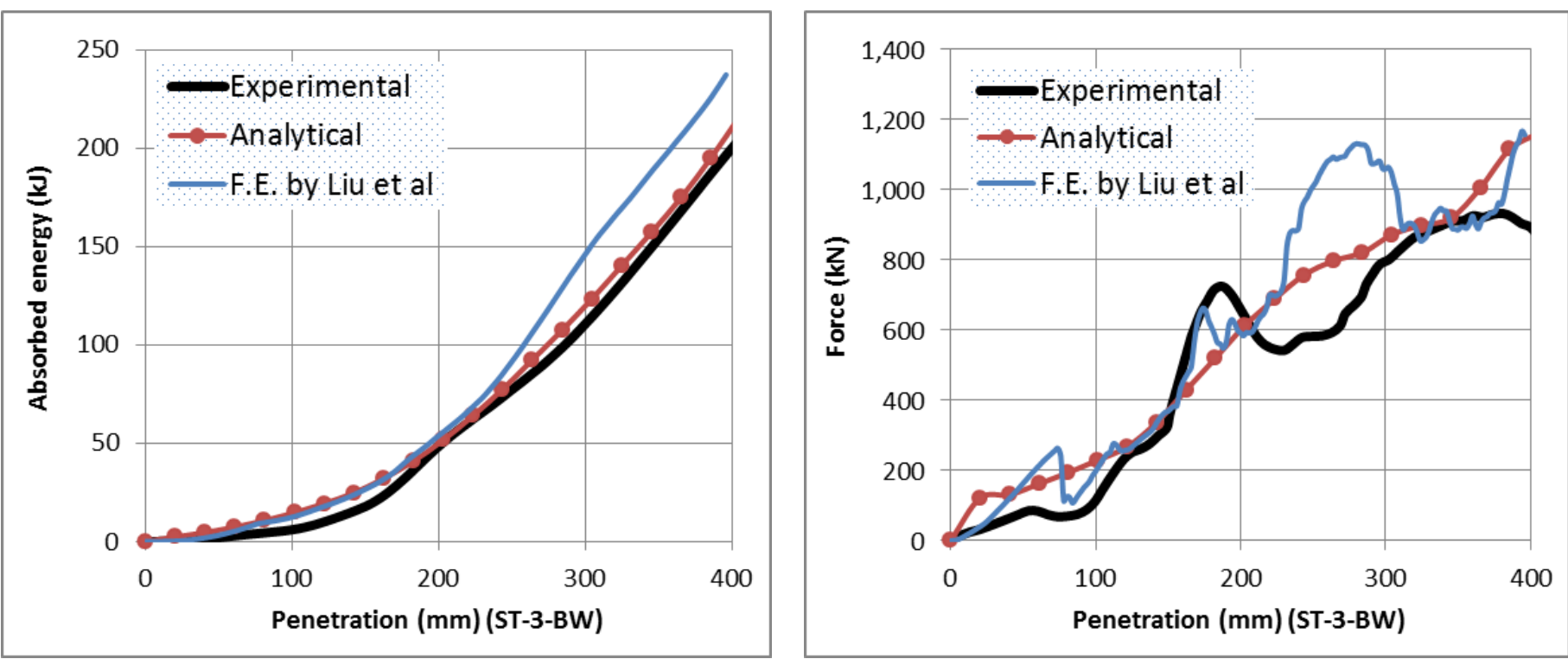

Figure 8: Energy-penetration and force-penetration curves: Model ST-3-BW 

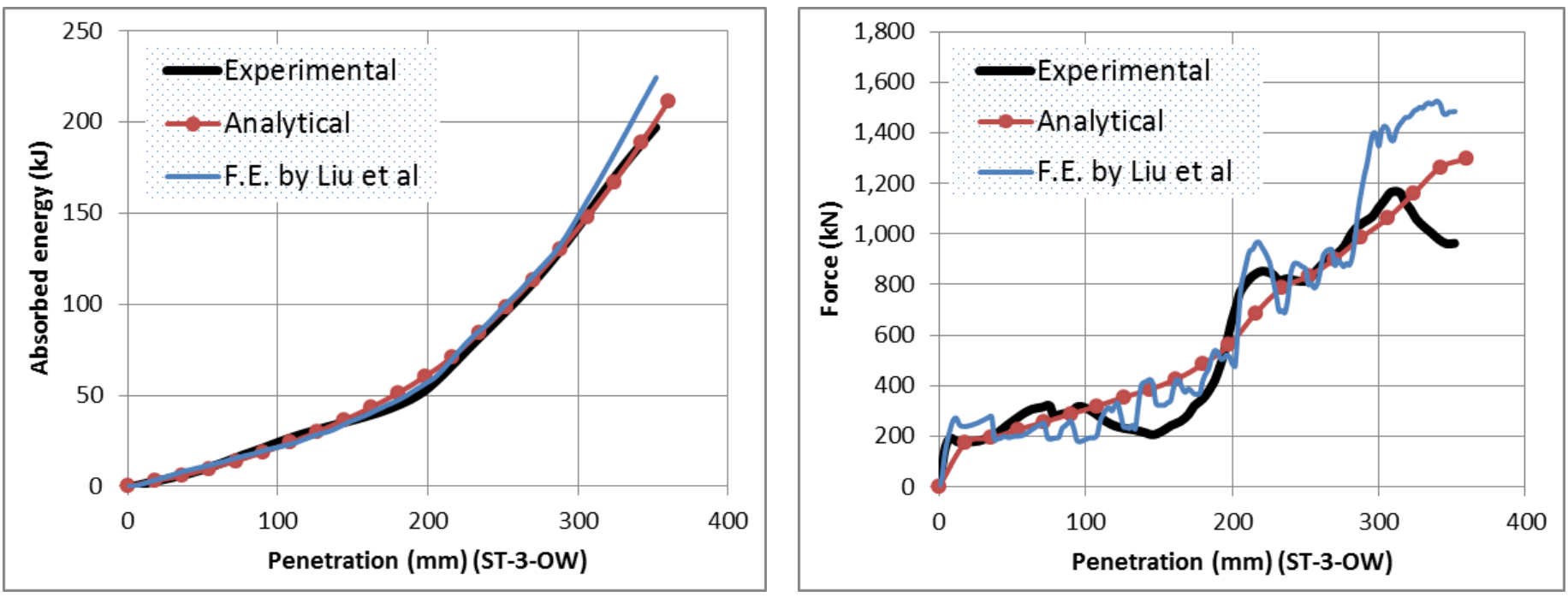

Figure 9: Energy-penetration and force-penetration curves: Model ST-3-OW
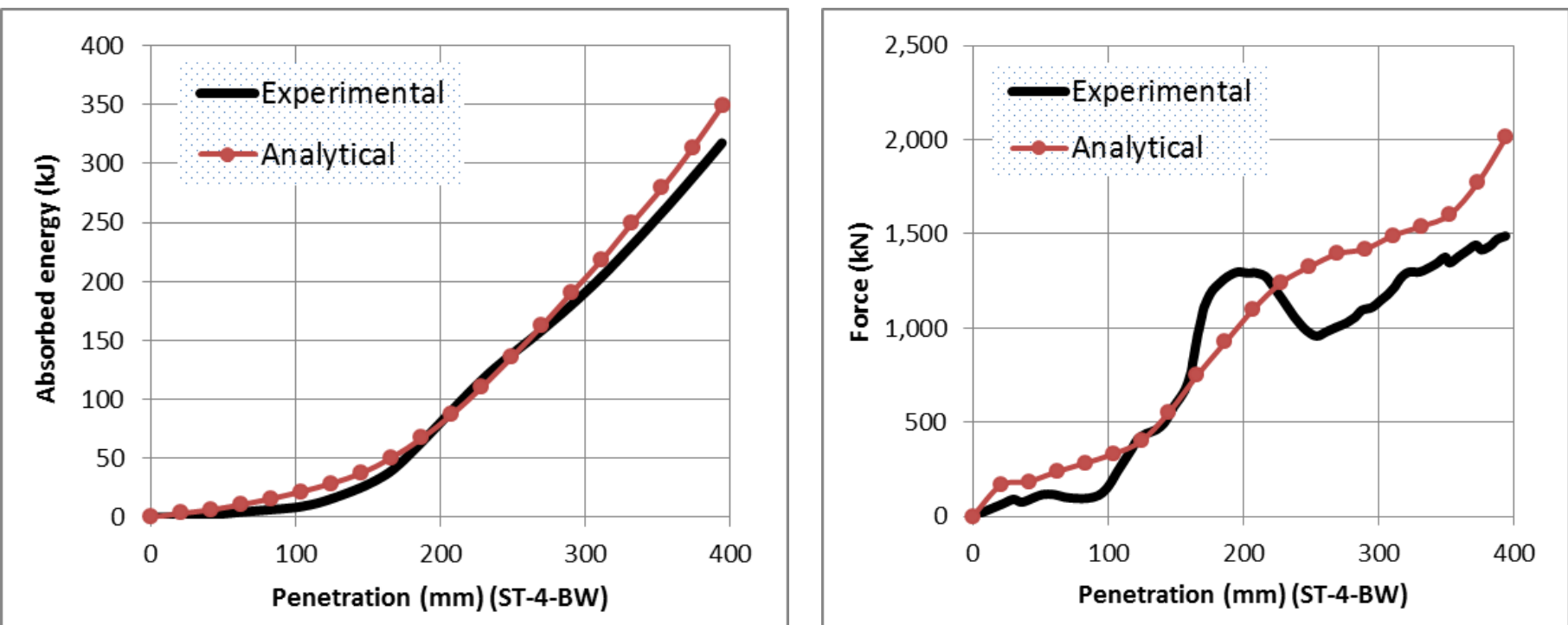

Figure 10: Energy-penetration and force-penetration curves: Model ST-4-BW
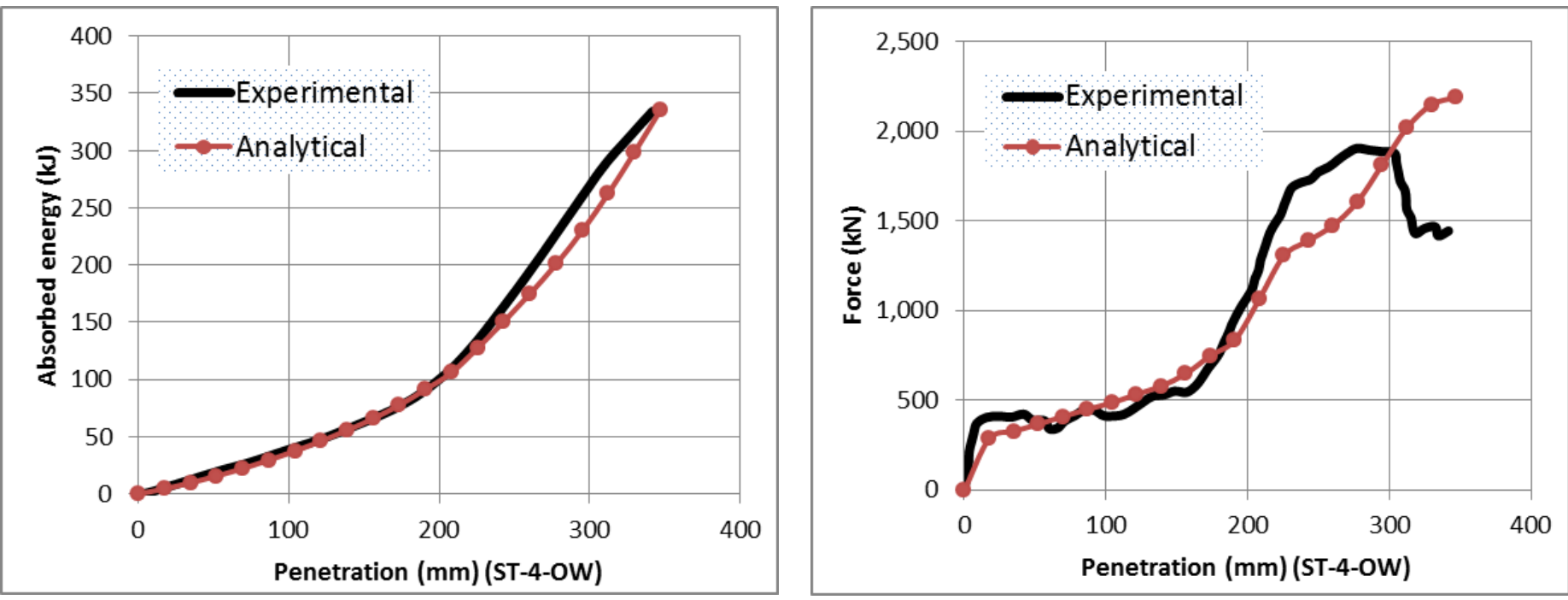

Figure 11: Energy-penetration and force-penetration curves: Model ST-4-OW 


\subsection{Nine model tests by Wang et al. [20]}

Collision tests of nine double hull models were carried out by Wang et al. [20]. The radius of the rigid conical indenter varies from a relatively sharp radius $R=10 \mathrm{~mm}$ to a relatively round radius $R=300 \mathrm{~mm}$. For all cases, the span between webs is $200 \mathrm{~mm}$, the depth of the specimens is $200 \mathrm{~mm}$, and the thickness of the outer and inner platting as well as that of the webs is $2.3 \mathrm{~mm}$. The penetration was enforced until reaching the inner hull and the collision positions were at three different locations: between the webs, on the webs and at the webs' intersection. The geometry of the specimens is illustrated in Fig. 12 together with the damage patterns of specimens P-100 and P-300 after collision tests. Details for each experiment and the material properties are summarised in Table 3.

The material is mild steel but the exact values of the material properties are not available in [20]. In the previous analytical calculations, reported in [3], the yield stress was taken as $282 \mathrm{MPa}$ and the ultimate stress as $400 \mathrm{MPa}$. The rupture strain was determined as 0.45 by calibrating the analytical results of model P-100 with its corresponding experimental results; friction effects were omitted. Although this magnitude of the rupture strain (0.45) is not unusual for Japanese steels, as also demonstrated by the uniaxial tensile tests performed by Ito et al. [21], the value of 0.45 can be considered as an upper limit for this material parameter. Therefore, after analysing material properties data from the shipbuilding industry, the properties given in Table 3 are found to be appropriate and used for the present calculations.

The absorbed energy-penetration and force-penetration curves for the nine models are compared and presented in Figs. 13 to 21. The finite element results of specimens P-50, P-100, P-200 and P-300 are taken from Liu et al. [15] where the mesh size is 9t. Overall, the analytical calculations follow the experimental response sufficiently. Further discussions will be presented in Section 5.
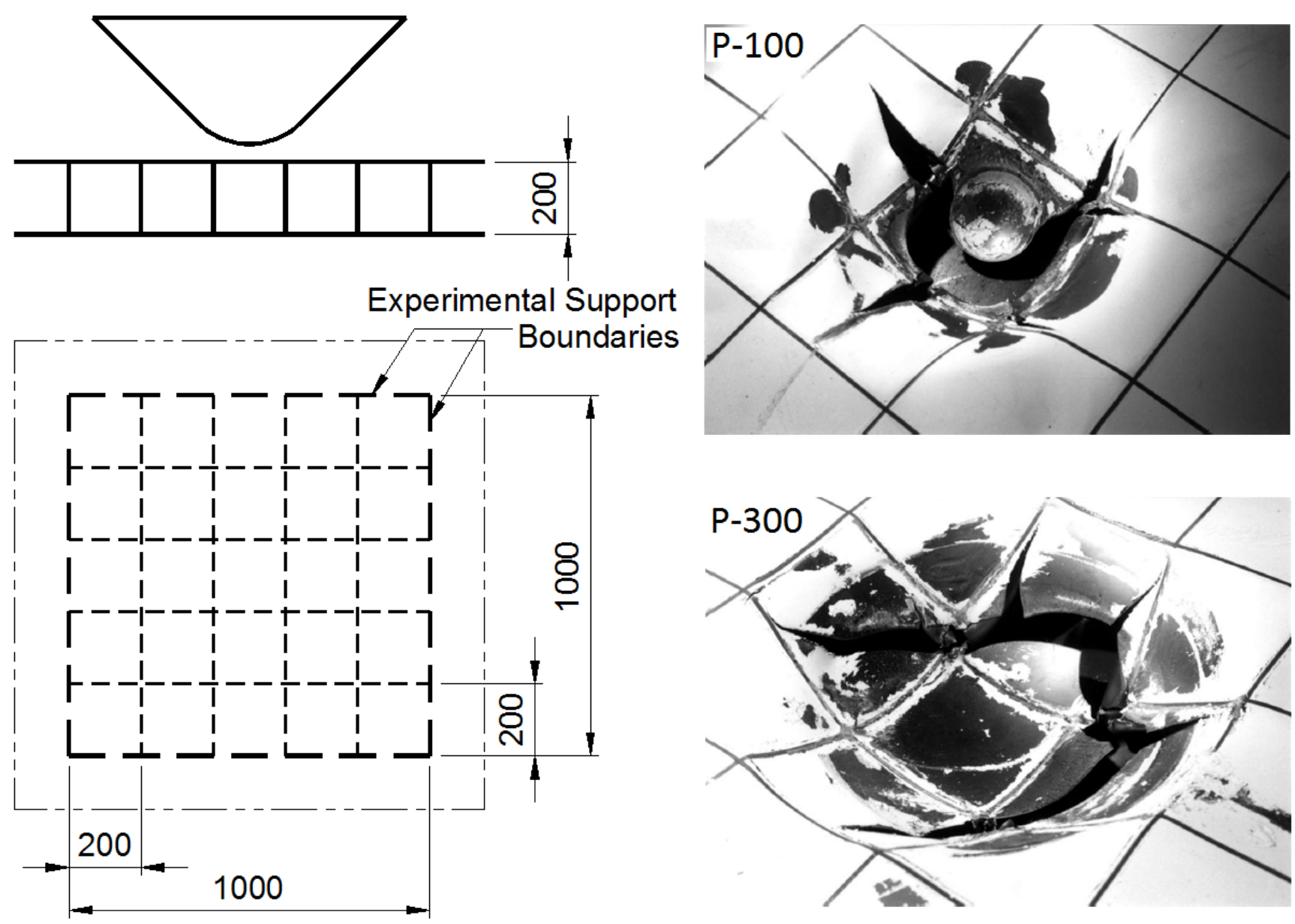

Figure 12: Illustration of Wang et al. [20] model tests and shape of deformation of specimens P-100 and P-300 
Table 6: Details and material properties of Wang et al. [20] experiments

\begin{tabular}{|c|c|c|c|c|c|c|c|}
\hline ID & Model & Cone radius (mm) & Contact location & Plate (mm) & $\sigma_{\mathrm{y}}(\mathrm{MPa})$ & $\sigma_{\mathrm{u}}(\mathrm{MPa})$ & $\varepsilon_{\mathrm{f}}(-)$ \\
\hline 8 & P-10 & 10 & Between webs & & & & \\
\hline 9 & P-50 & 50 & Between webs & & & & \\
\hline 10 & P-100 & 100 & Between webs & & & & \\
\hline 11 & P-200 & 200 & Between webs & & & & \\
\hline 12 & P-300 & 300 & Between webs & 2.3 & 282 & 438 & 0.35 \\
\hline 13 & W-50 & 50 & On web & & & & \\
\hline 14 & W-200 & 200 & On web & & & & \\
\hline 15 & C-50 & 50 & Intersection of webs & & & & \\
\hline 16 & C-200 & 200 & Intersection of webs & & & & \\
\hline
\end{tabular}
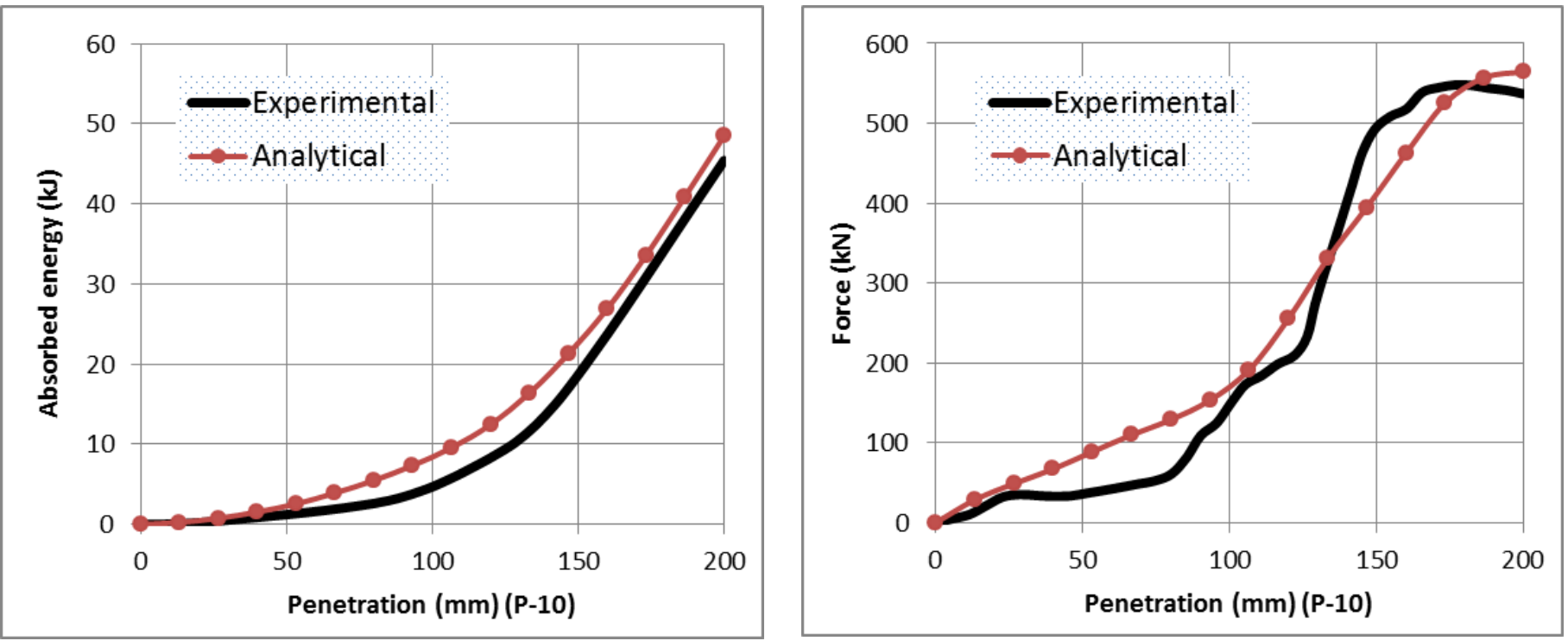

Figure 13: Energy-penetration and force-penetration curves: Model P-10
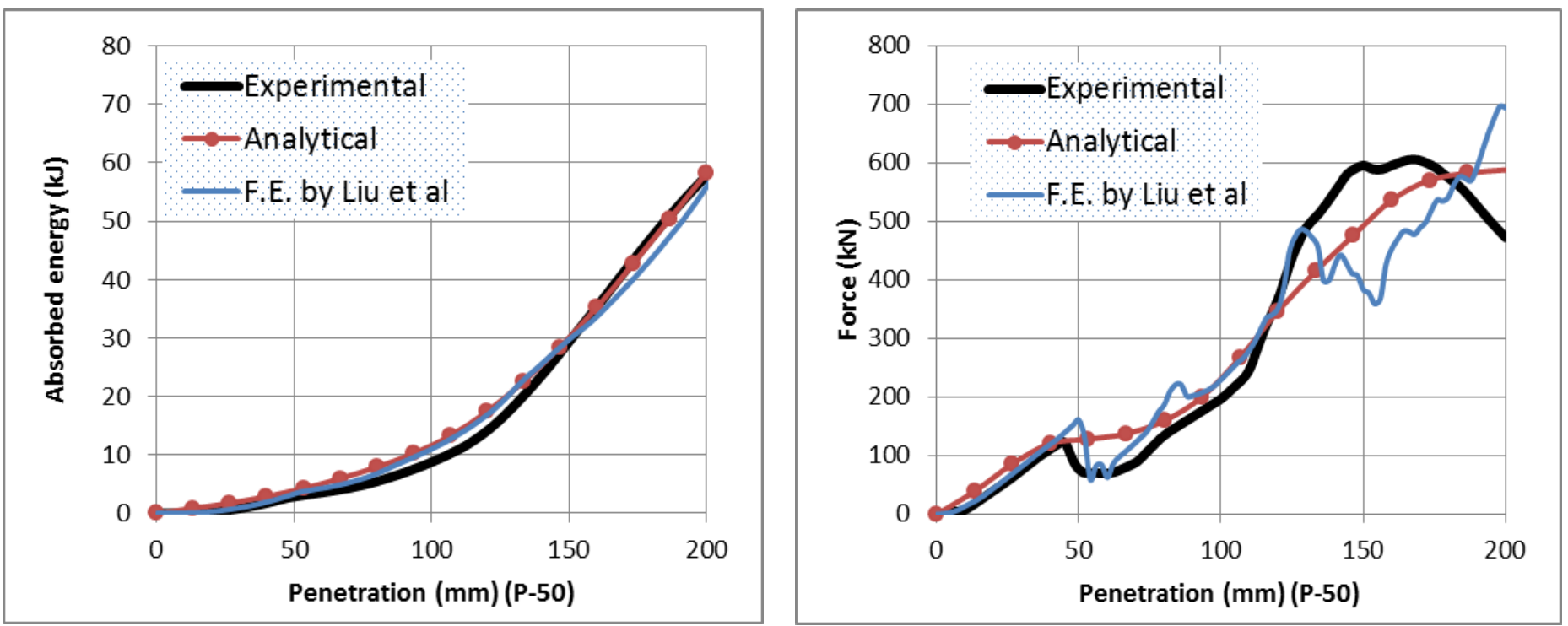

Figure 14: Energy-penetration and force-penetration curves: Model P-50 

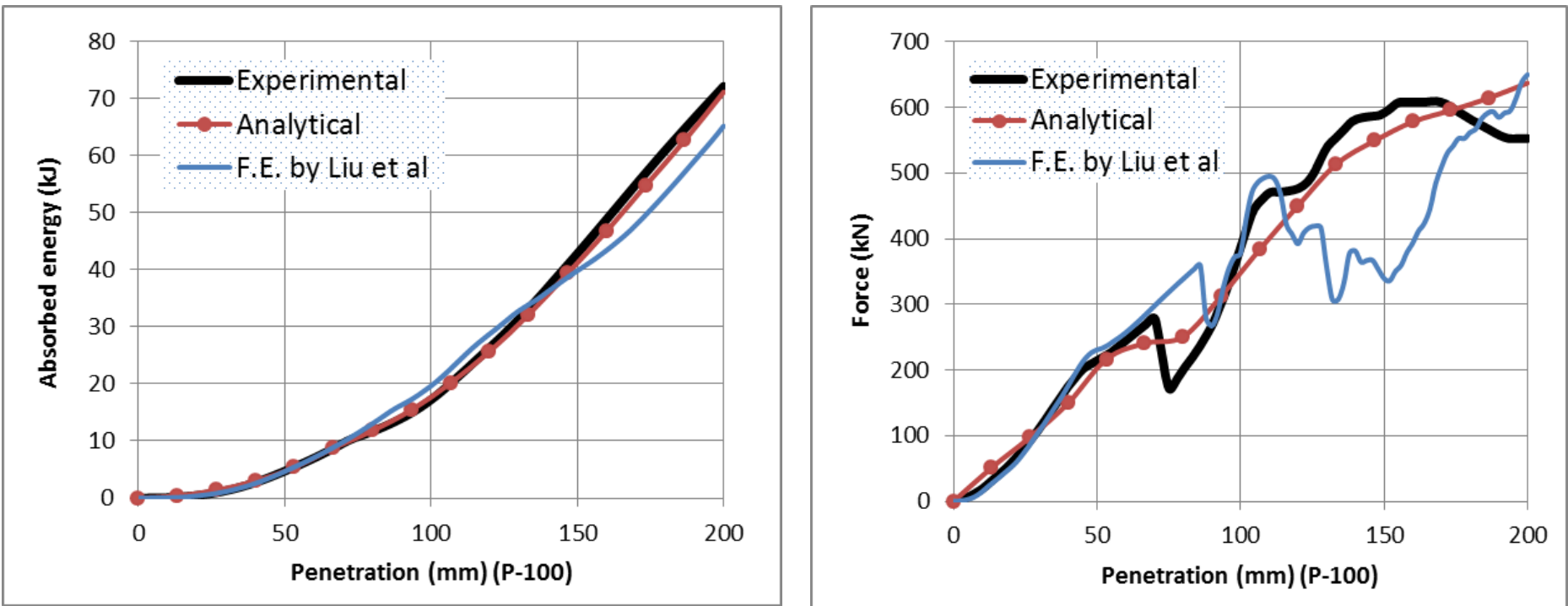

Figure 15: Energy-penetration and force-penetration curves: Model P-100
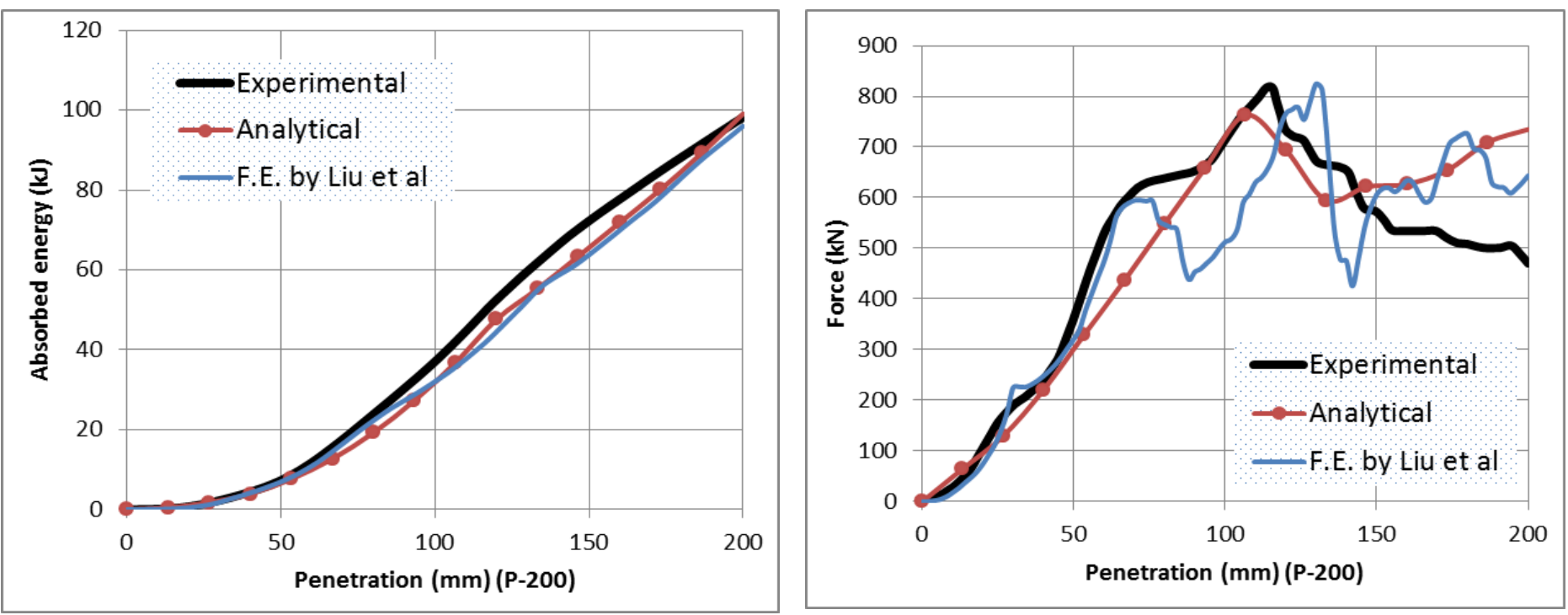

Figure 16: Energy-penetration and force-penetration curves: Model P-200
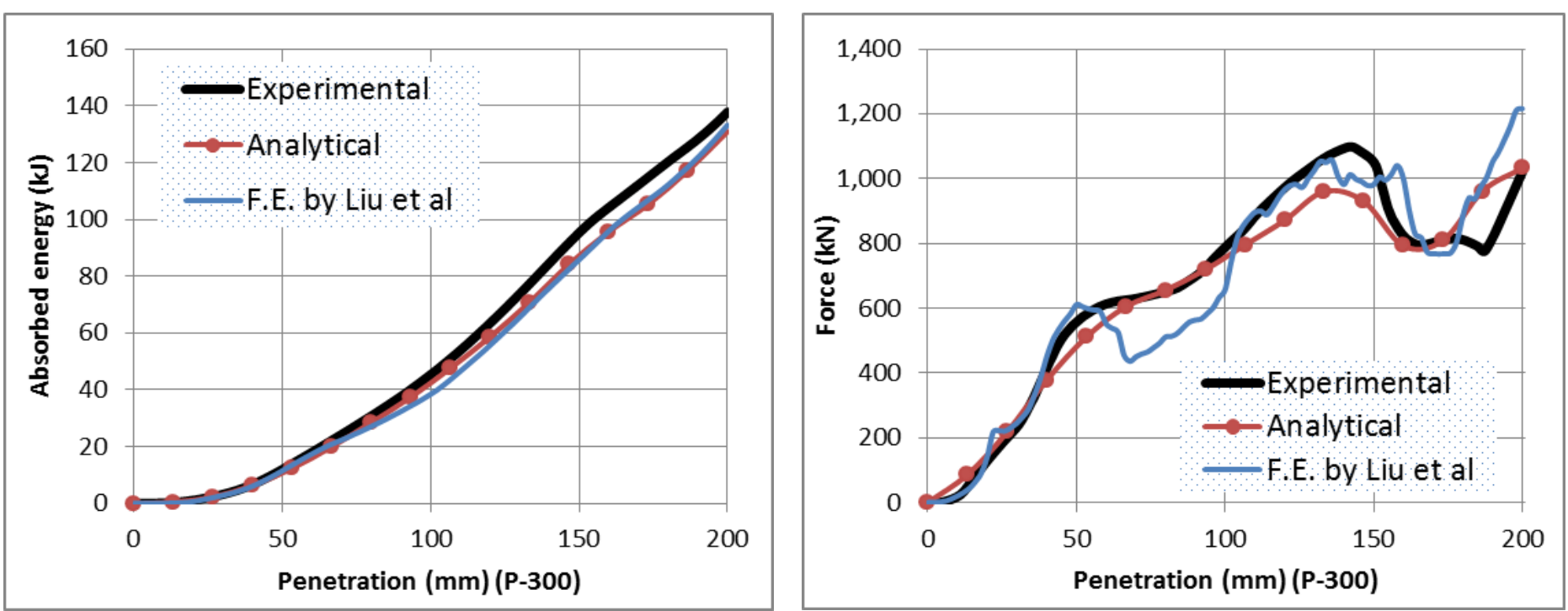

Figure 17: Energy-penetration and force-penetration curves: Model P-300 

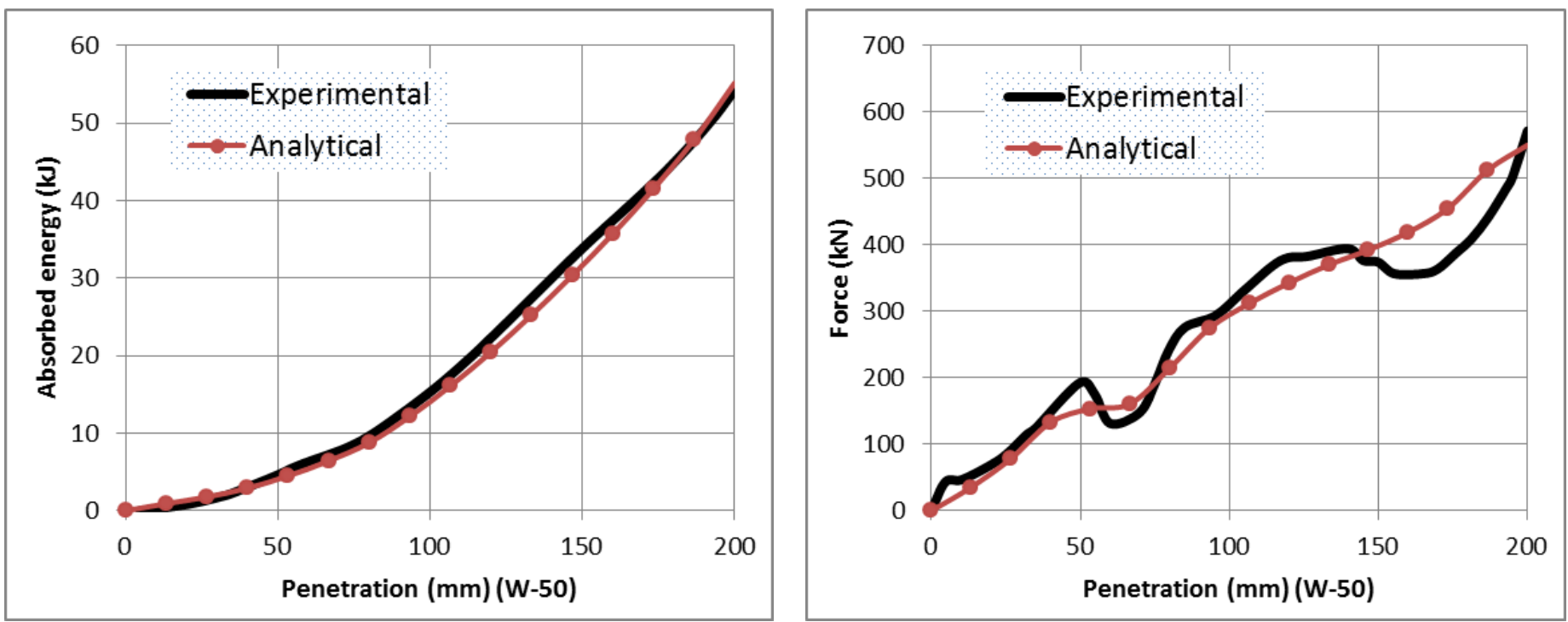

Figure 18: Energy-penetration and force-penetration curves: Model W-50
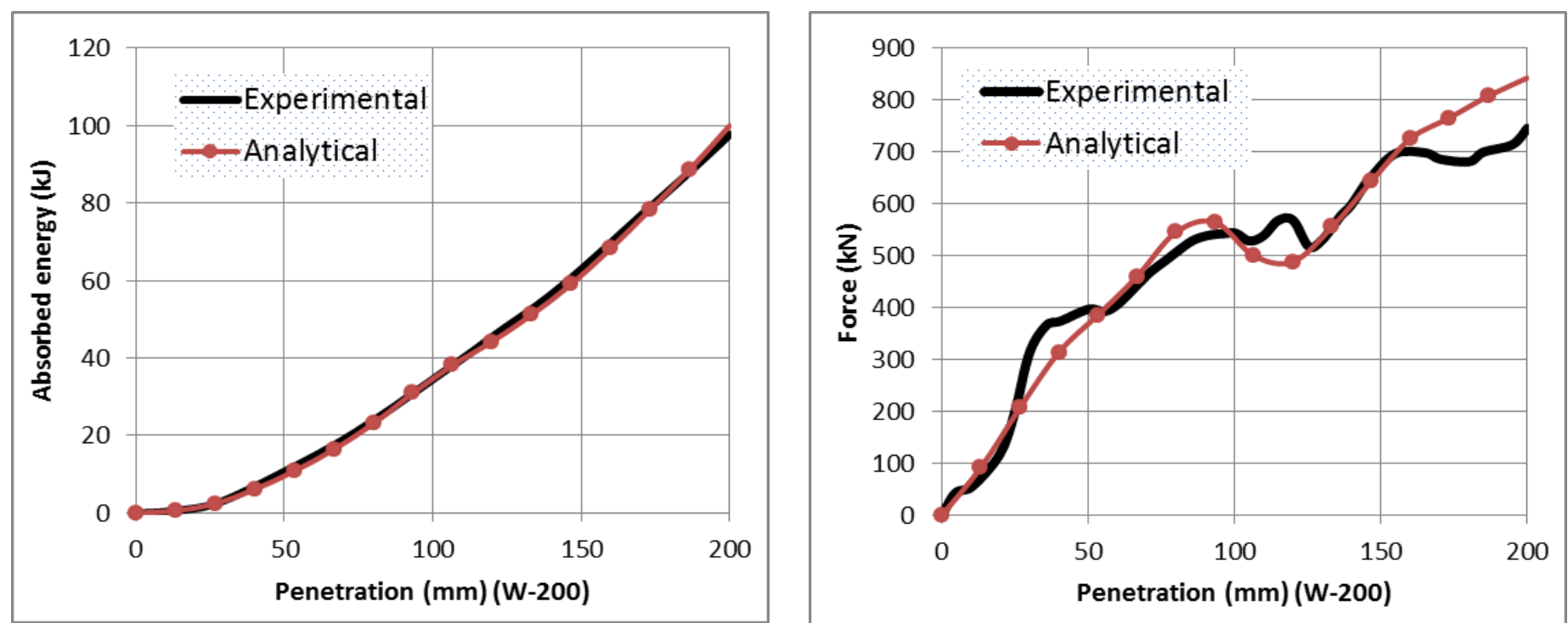

Figure 19: Energy-penetration and force-penetration curves: Model W-200
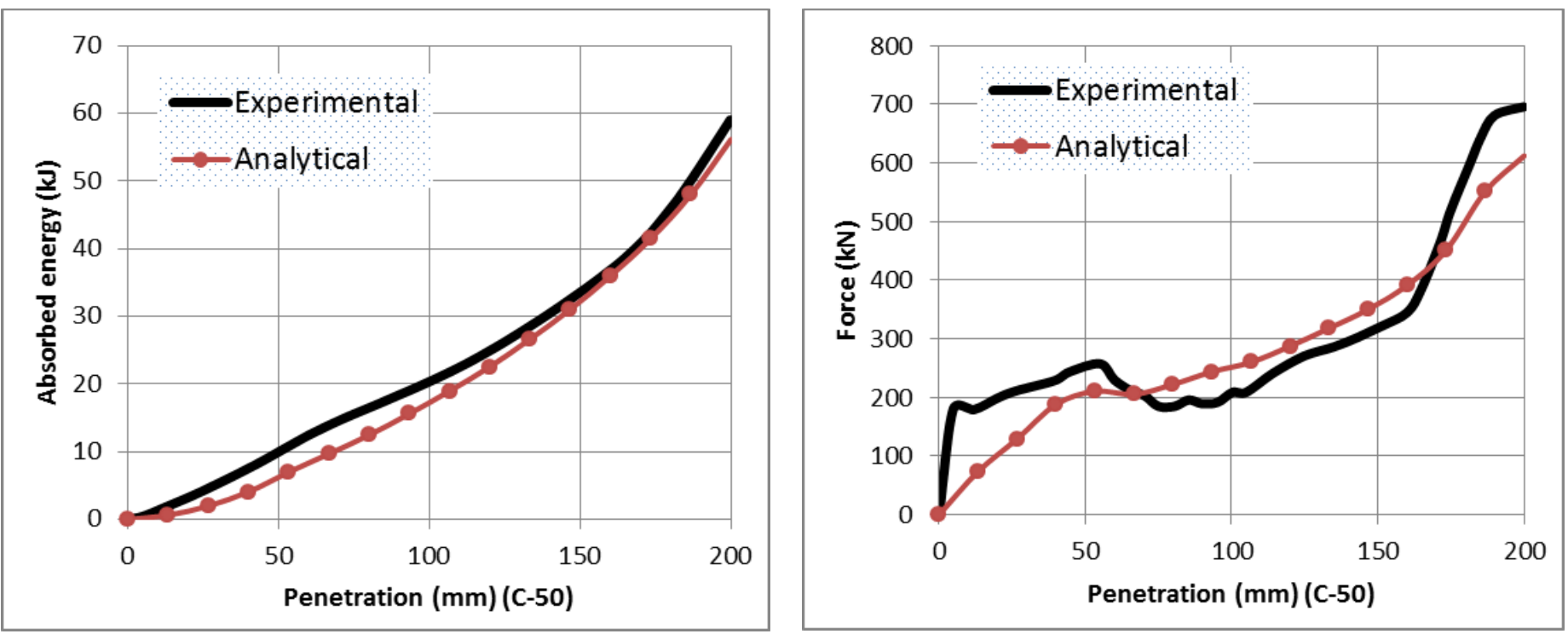

Figure 20: Energy-penetration and force-penetration curves: Model C-50 

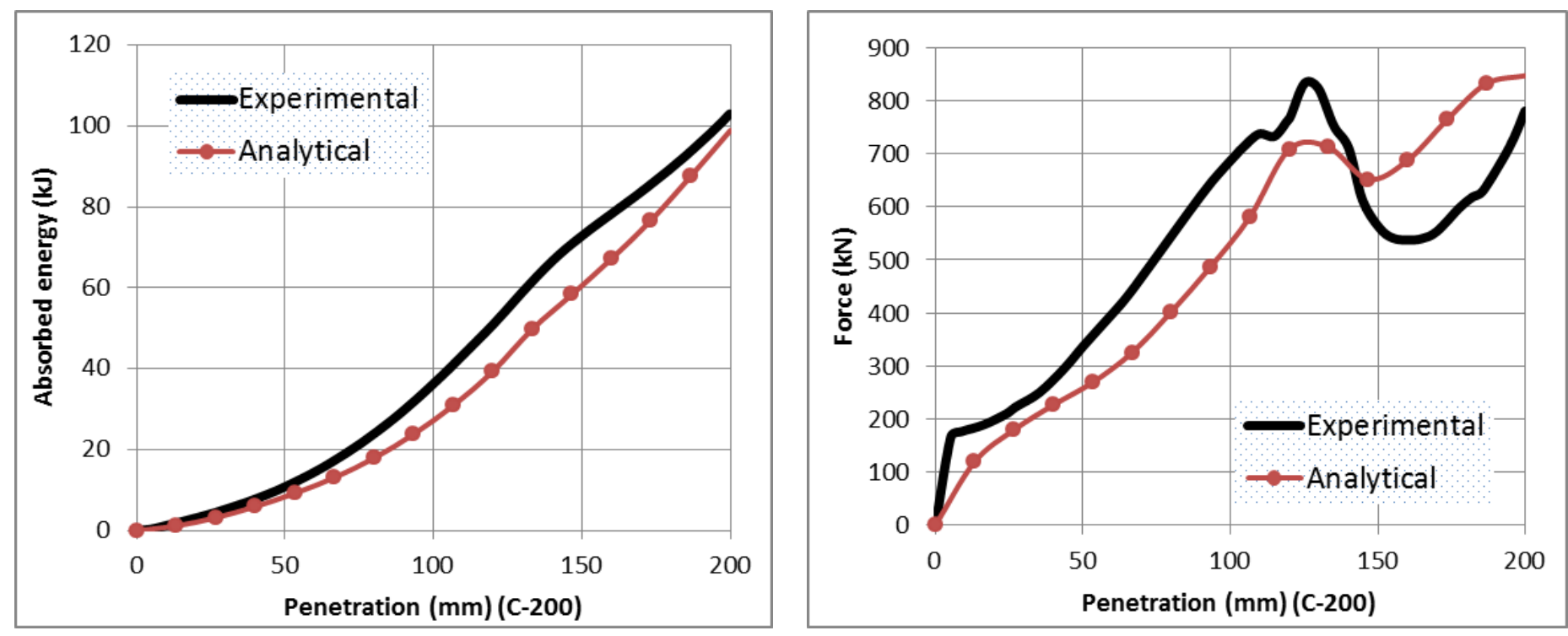

Figure 21: Energy-penetration and force-penetration curves: Model C-200

\subsection{Model test by Tautz et al. [22]}

Tautz et al. [22] performed laboratory collision experiments with a rigid bulbous bow driven against models of double hull side structures, as shown in Fig. 22.

The thickness was $4.0 \mathrm{~mm}$ for both the top and the bottom plates stiffened by bulb profiles HP 140x7 spaced at $280 \mathrm{~mm}$. The web frames of thickness $5.0 \mathrm{~mm}$ were spaced at $800 \mathrm{~mm}$. The total height from the top to the bottom plate was $900 \mathrm{~mm}$. A sketch of the model test and the rigid bulb is illustrated in Fig. 22 together with the deformed shape of specimen CE-1. The materials properties obtained from tensile tests are given in Table 4.

Both the top and bottom plates were fully penetrated (see Fig. 22), and thus the experiment represents a good opportunity to validate theoretical methods for severe collisions. For the top and bottom stiffened plates, the cross sectional area of the stiffeners is smeared into the plates as suggested by Zhang [1].

The absorbed energy-penetration and force-penetration curves are presented in Fig. 23. The finite element results are taken from Tautz et al. [22]. While the analytical calculations overestimate a bit the energy response before the penetration of about $800 \mathrm{~mm}$, the agreement beyond that point is very good.

Table 4: Material properties of the top and bottom plate: Tautz et al. [22]

\begin{tabular}{cccccc}
\hline ID & Model & Plate thickness $(\mathrm{mm})$ & $\sigma_{\mathrm{y}}(\mathrm{MPa})$ & $\sigma_{\mathrm{u}}(\mathrm{MPa})$ & $\varepsilon_{\mathrm{f}}(-)$ \\
\hline 17 & CE-1 & 4.0 & 340 & 460 & 0.32 \\
\hline
\end{tabular}



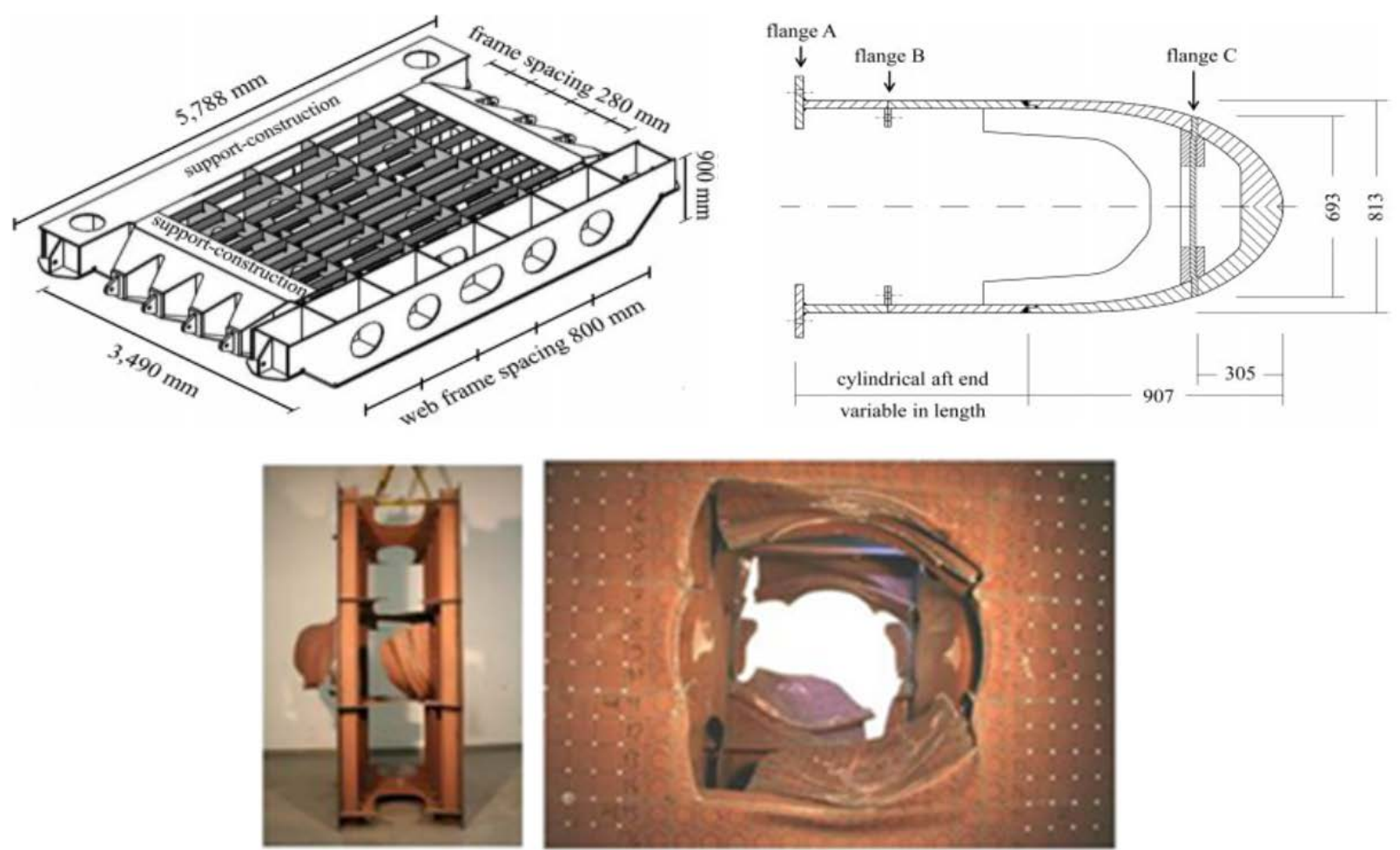

CE-1

Figure 22: Illustration of Tautz et al. [22] collision experiment CE-1, cf. Tautz et al. [22]
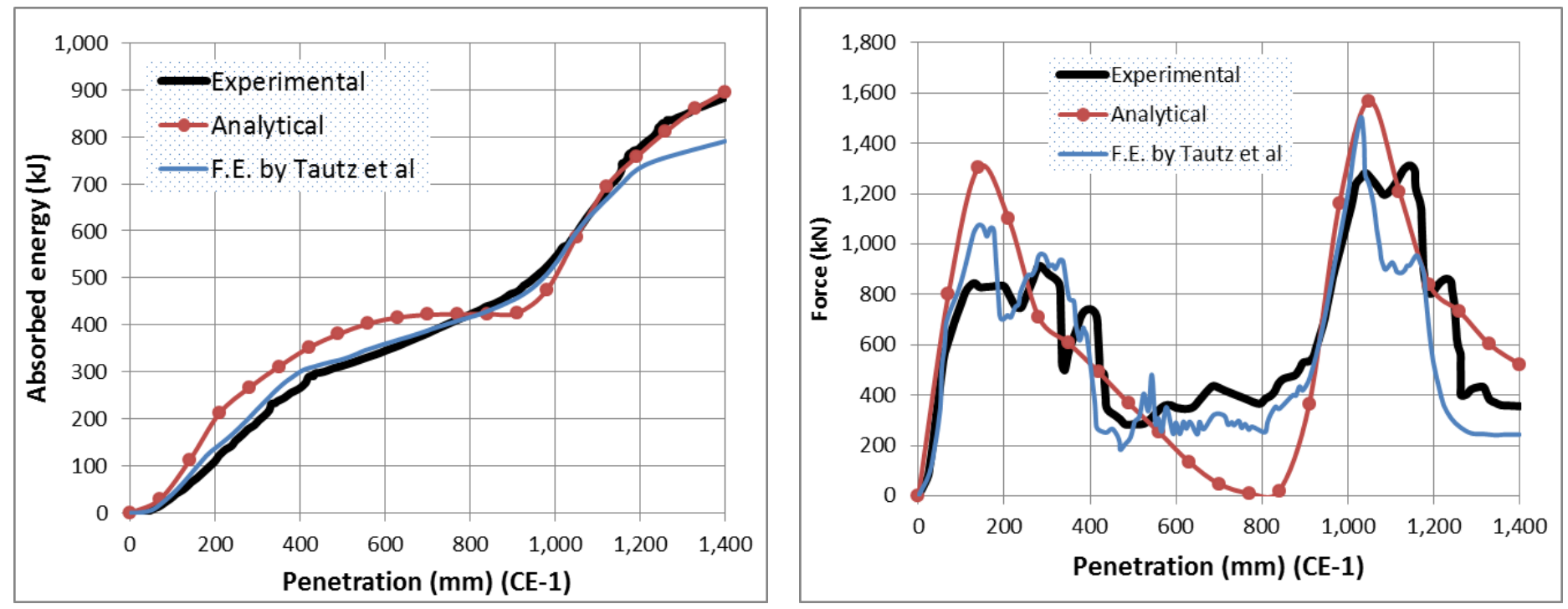

Figure 23: Energy-penetration and force-penetration curves: Model CE-1

\subsection{Large scale model test by Lehmann and Peschmann [23]}

Lehmann and Peschmann [23] reported the results of a large-scale collision test carried out in association with the Organisation for Applied Scientific Research (TNO) in the Netherlands. This collision test can be also found in Peschmann [24].

Two inland waterway vessels of about $80 \mathrm{~m}$ length were used in the collision tests, as illustrated in Fig. 24. A double hull structure (referred here as model test) was inserted at the mid-ship region of the struck ship, representing 1/3 of a medium size double hull tanker of approximately 30,000 DWT. The dimensions of the model test were: length $7.5 \mathrm{~m}$, double side width $0.7 \mathrm{~m}$, and total height $4.2 \mathrm{~m}$. The thickness of the outer and inner shell plating was $5.0 \mathrm{~mm}$ stiffened by flat bars FB $100 \times 5.0 \mathrm{~mm}$ equally spaced at $225 \mathrm{~mm}$. The vertical webs were $6.0 \mathrm{~mm}$ thickness spaced at $1125 \mathrm{~mm}$, while the horizontal stringers were $5.0 \mathrm{~mm}$ thickness spaced at $1130 \mathrm{~mm}$. The striking ship was fitted with a rigid bulbous bow and the collision speed was $2.55 \mathrm{~m} / \mathrm{s}$. 
As ship motions occurred during the collision, this test is considered a rather complicated experiment. Since a large penetration was achieved during the test, both the outer and inner hulls suffered severe damage, providing valuable information for validating theoretical methods.

The materials properties were obtained from standard uniaxial tensile tests. Peschmann [24] reported that scratches on the model after the collision were very small, and hence the friction coefficient used in their finite element analysis was relatively small $(\mu=0.1)$, and this gave the best agreement with the experimental results. Considering that the contribution of friction to the total absorbed energy is quite small, the friction effect is ignored in the analytical calculation, as it also provides good agreement with the experimental results.

The absorbed energy-penetration and force-penetration curves are presented in Fig. 25. The finite element results are taken from Lehmann and Peshmann [23]. It is seen from the comparison that the analytical method gives an excellent agreement with the experimental results for such complicated collision test.
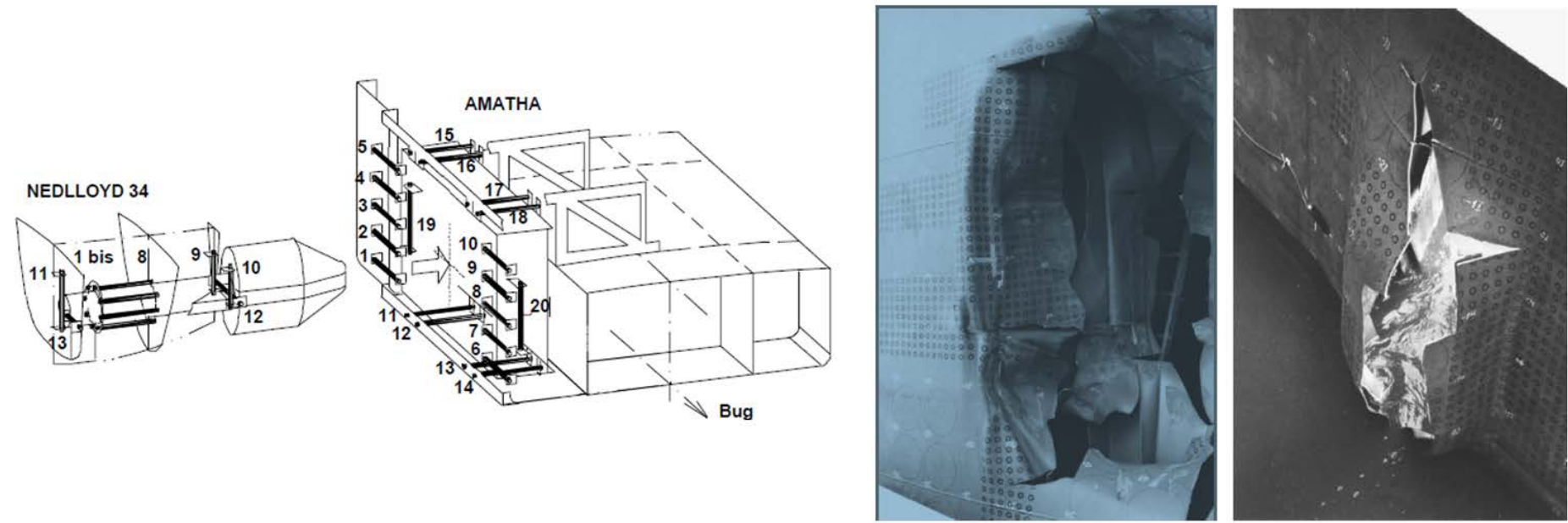

Figure 24: Large-scale collision experiment in the Netherlands, cf. Peschmann [24]
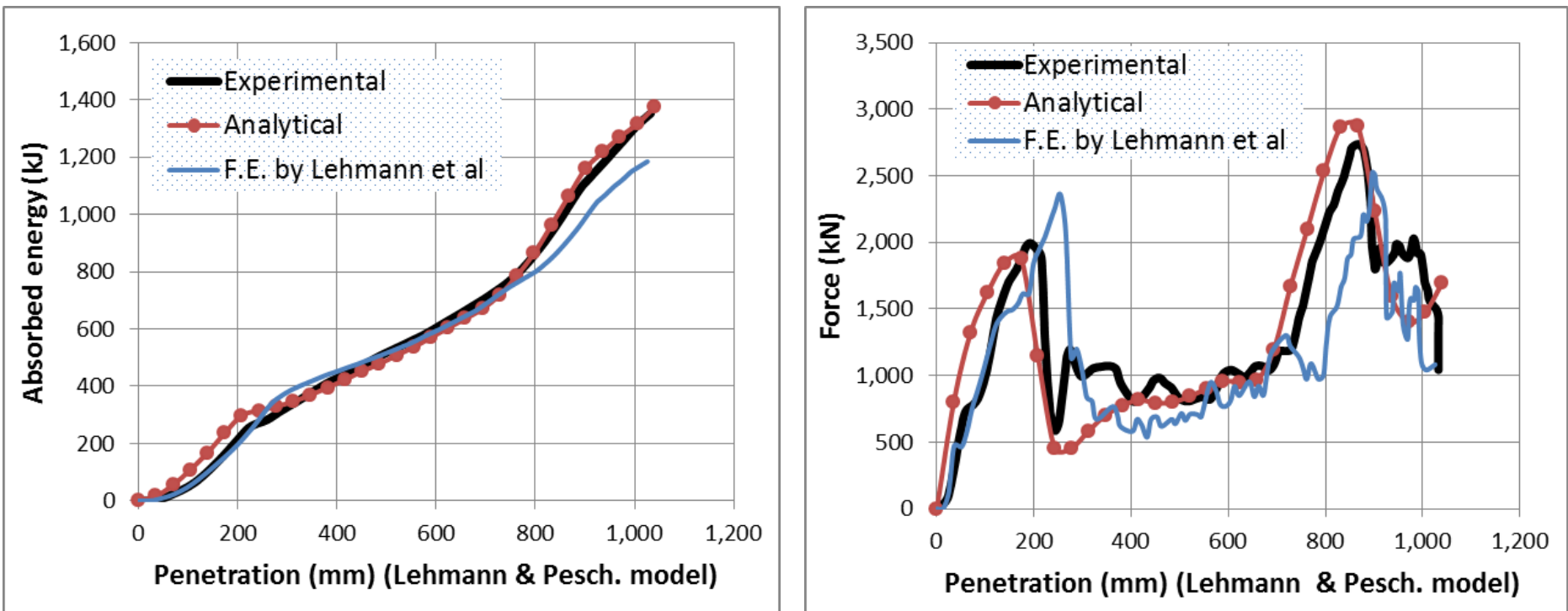

Figure 25: Energy-penetration and force-penetration curves: Model Lehmann \& Peshmann

\subsection{Full-scale collision accident reported by Martens [12]}

Martens [12] reported a full-scale collision accident in the German harbor Travemünde in 2012. The collision occurred between the RoPax vessels URD (struck ship) and NILS HOLGERSSON (striking ship). Martens [12] also performed a detailed finite element analysis of the collision accident; the outcomes of the analysis can be also found in Storheim et al. [14]. 
The struck vessel was moored alongside the quay when the striking vessel lost control during maneuvering and impacted the struck vessel at 6.5 knots. The impact direction and velocity were determined from AIS data. The struck ship suffered considerable damage both above and below the waterline, whereas the striking ship received only minor plate dents (Fig. 26), as the NILS HOLGERSSON is an ice strengthened ship. The maximum indentation into the struck vessel was $7.6 \mathrm{~m}$ at the upper deck level and about $4.6 \mathrm{~m}$ at the waterline level (measured from the ship side) $[12,14]$.

The mass of the NILS HOLGERSSON was 20,500 tons at the draught she had at the impact. The added mass of the vessel was unknown, but it may have been increased as a result of shallow water effects due to the shallow depth $(10 \mathrm{~m})$ of the harbor. Under the assumption of $10 \%$ added mass, the total available kinetic energy was estimated at $126.5 \mathrm{MJ}[12,14]$.

In the finite element simulations [12], the struck vessel was simply supported along its centerline, and the striking vessel assumed to have only a longitudinal degree of freedom. Martens [12] estimated that with these assumptions, 12.1 MJ of the dissipated energy was consumed by the motions of the striking and struck vessels and the deflection of the fender system along the quayside. This leaves 114.4 MJ dissipated through strain energy and friction.

The yield stress of the materials used in the present analytical calculation is the same as defined by Martens [12] and Storheim et al. [14] in the FE simulations. On the other hand, the ultimate tensile stress and the rupture strain are estimated based on material data from the shipbuilding industry and are given in Table 5.

The comparison between the analytical calculation and the FE simulation results is shown in Fig. 27; good agreement is observed.

Table 5: Material properties used in analytical calculation

\begin{tabular}{ccccc}
\hline ID & Model & $\sigma_{\mathrm{y}}(\mathrm{MPa})$ & $\sigma_{\mathrm{u}}(\mathrm{MPa})$ & \\
\hline 19 & RoPax URD incident & 314 & 462 & 0.33 \\
\hline
\end{tabular}
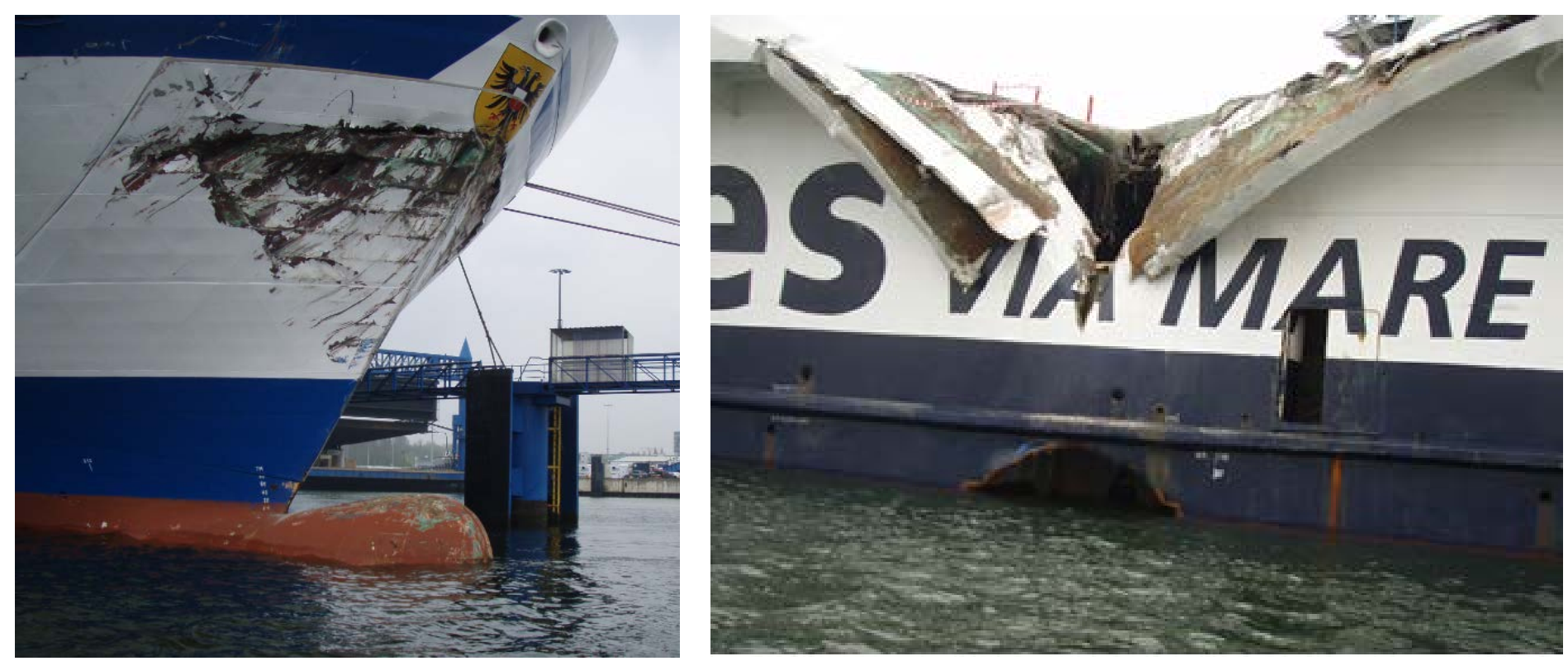

Figure 26: Damages in the RoPax URD accident, cf. Martens [12] 

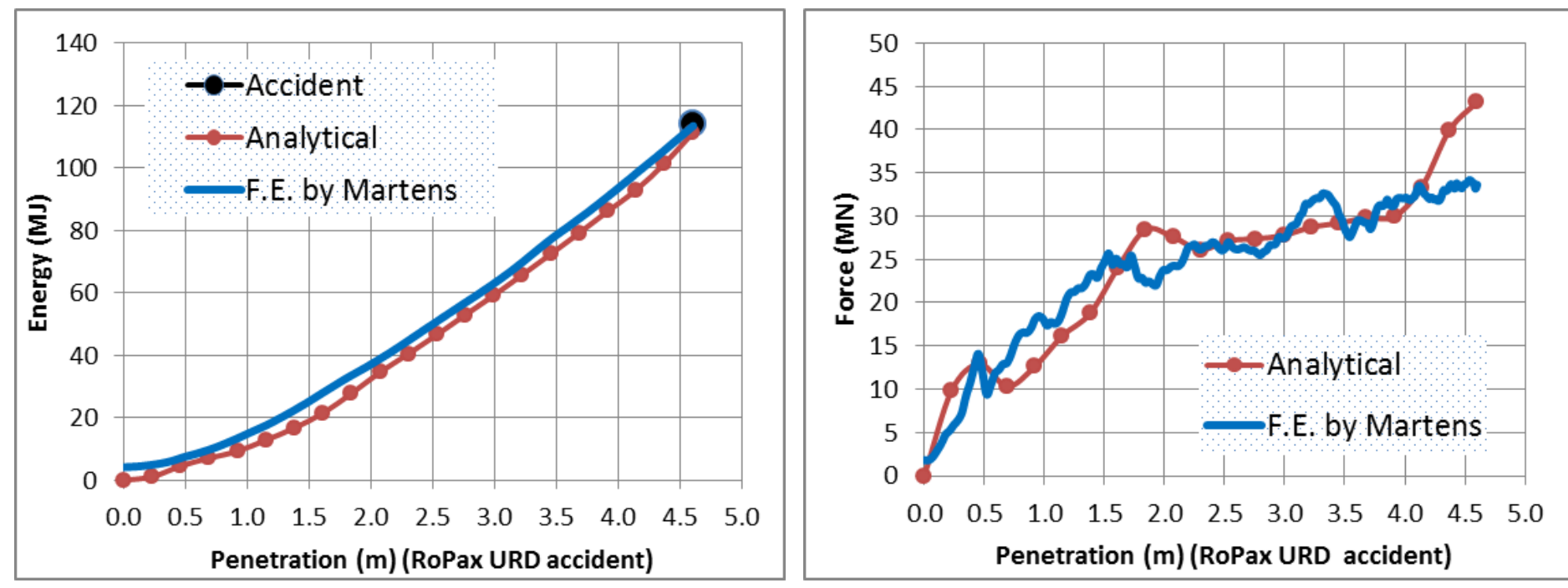

(Note: penetration in this figure is measured from the ship side at waterline level)

Figure 27: Energy-penetration and force-penetration curves: RoPax URD accident

\section{Discussion}

In Section 4, the predictions of the analytical method are compared with 18 experiments and one real ship-toship collision accident. In general, the analytical calculations follow the experimental response with good accuracy.

From the three FE simulations of the experiments by Arita and Aoki [17], it can be observed that the energy and impact force responses are not particularly improved by the finite element results. In fact, the energy- and force-displacement curves are better predicted by the analytical method for specimens S-II and S-III. For specimen S-I, both the analytical method and FEA have reached a similar reasonable agreement with the experimental results.

The comparisons with specimens ST-3-BW and ST-4-BW, in Section 4.2, also exhibit that the analytical calculations estimate the energy response better than the FE simulations. It should be noted that here, the material parameters are obtained from uniaxial tensile tests, and consequently the material uncertainty is diminished. In spite of some deviations with the force-displacement curves, all analytical calculations predict accurately for the energy absorbed during the entire impact event. It should be recalled that the calculated collision force only represents the mean value of each analyzed step and it does not reflect the peak force caused by buckling in experiments, as discussed in Section 2.

The predictions of the experiments of Wang et al. [20] lead to more challenges for both the analytical method and FEA, as the radius of the indenters varies considerably and the impact occurs at different locations. For the collisions with the center of the indenter positioned between webs, the analytical calculations follow the 'entire' energy-displacement response quite well, and even better than the FEA simulations. For the impacts on web (W-50 and W-200) and at intersection of webs (C-50 and C-200), the analytical calculations also follow the energy response reasonably well.

For the model of Tautz et al. [22], the analytical calculation follows the experimental curves relatively good, though it overestimates a bit the energy absorption before the penetration reached at $800 \mathrm{~mm}$, while beyond this point the predictions are quite accurate. The special feature of this test model, which is different from the models discussed above, is that the model was made from stiffened panel, e.g. it has stiffeners on the outer and inner bottoms. Smearing the stiffeners to the equivalent plate seems to work well.

The large-scale collision test by Lehmann and Peschmann [23] is definitely the more complex scenario presented here. However, the analytical approach predicts the experimental response very well. 
The analytical calculation of the full-scale collision accident is also quite good when compared with the FEA simulations. The energy estimated at the end of the collision is close enough to the actual data. This agreement, as well as that with the large-scale collision test, highlights the accuracy and practicality of the analytical method.

The analysis of all the results presented here indicates that the analytical method can be used for collision assessments with a good degree of confidence when it is required to estimate the extent of structural damage.

It should be mentioned that one practical application of this method has already been established. This analytical procedure is recommended in the recently published Guidance Notes for Collision Assessment for the Location of Low-flashpoint Fuel Tanks [9]. Another example of the proposed analytical procedure is presented in Section 6.

\section{Application example: LNG carrier struck by a container ship}

It is a concern in the industry that LNG carriers during the loading and/or unloading at ports could be struck by ships entering the ports, such as illustrated by the example in Section 4.6. As the characteristic bow of some ships is relatively sharp, the consequence of such collision would be significant with potential gas leakage into the port and surrounding areas. In order to avoid such a situation it is of interest to determine the maximum critical speed that a typical striking ship will have before the LNG cargo tank boundary is reached.

An LNG carrier with 270 meters in length is selected for this application example. The main dimensions of the LNG carrier are shown in Table 6 together with those of a striking container ship. The collision scenario assumes that the LNG carrier is fully loaded and it is hit by the fully loaded container ship while waiting for discharging cargo. It is also assumed that the LNG carrier is stationary and floating freely before the perpendicular collision occurs at any location along its length (see Fig. 28). The task is to determine the critical speed of the striking container ship so that the inner hull of the LNG carrier remains intact.

The width of the double hull side structure is $2.5 \mathrm{~m}$, and thus the critical penetration was set at $2.5 \mathrm{~m}$ to avoid potential leakage of the cargo containment system.

The first step of the analysis is to determine the energy-penetration curves using the present analytical approach and it is obtained (see Fig. 29). The calculation results show that the structure of the LNG carrier can absorb $105 \mathrm{MJ}$ at the critical penetration of $2.5 \mathrm{~m}$.

The next step is to determine the critical collision speeds resulting in the collision energy of 105 MJ. Here, the analytical method developed by Zhang and Pedersen [25] is used for the analysis and the results are also presented in Fig. 29.

It is seen from the analysis results that the critical striking speed of the container ship is 4.2 knots for the collision at amidship of the LNG carrier. When the collision location is at $20 \%$ ship length (from the aft perpendicular), the critical striking speed is 5.2 knots. It may be concluded that if the container ship is managed and controlled within a speed limit of 4.2 knots, in the port and surrounding areas, the risk of causing LNG cargo leakage in the event of a collision can be very small.

Table 6: Main particulars of the striking and struck ships

\begin{tabular}{ccccc}
\hline ID & Ship & Length $(\mathrm{m})$ & Breadth $(\mathrm{m})$ & Depth $(\mathrm{m})$ \\
\hline 20 & LNG carrier (struck) & 270 & 44.0 & 26.0 \\
& Container ship (striking) & 230 & 32.2 & 21.1 \\
\hline
\end{tabular}



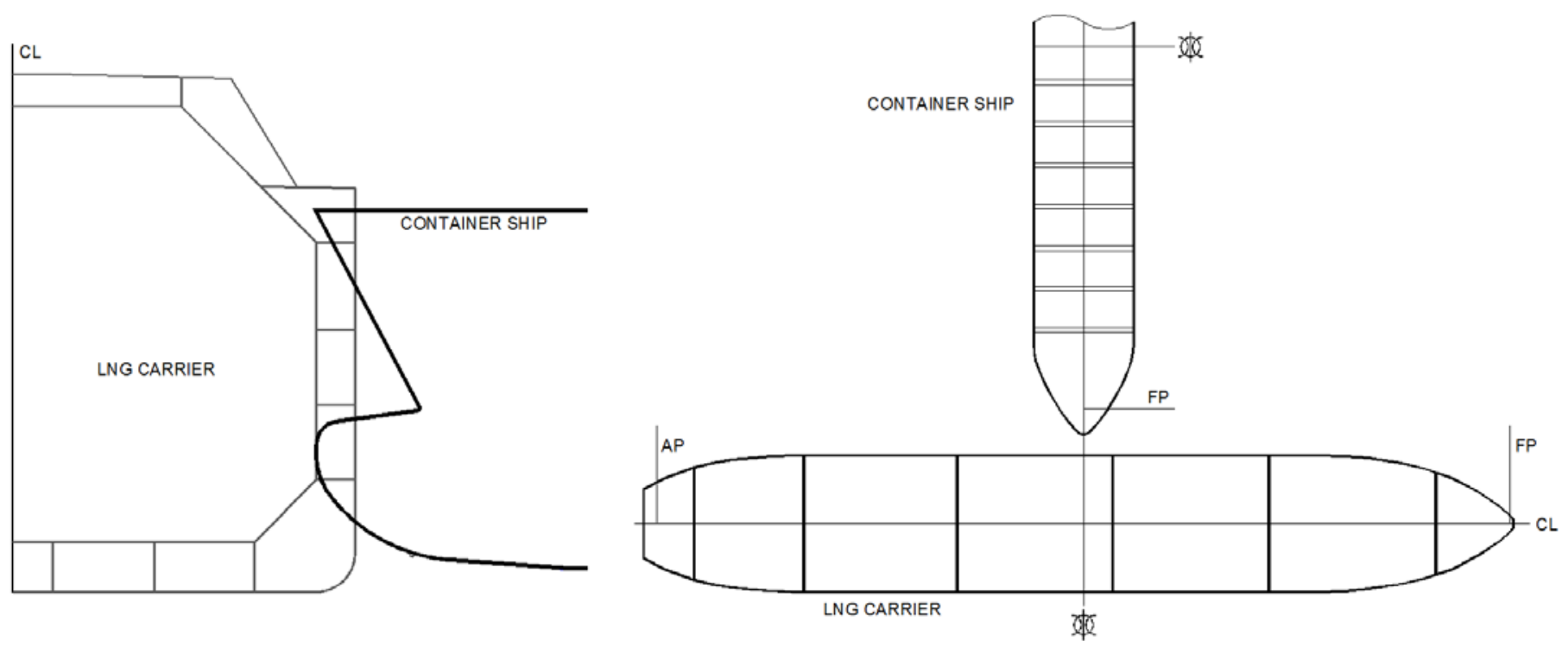

Figure 28: Sketch of the LNG ship and the container ship collision scenario
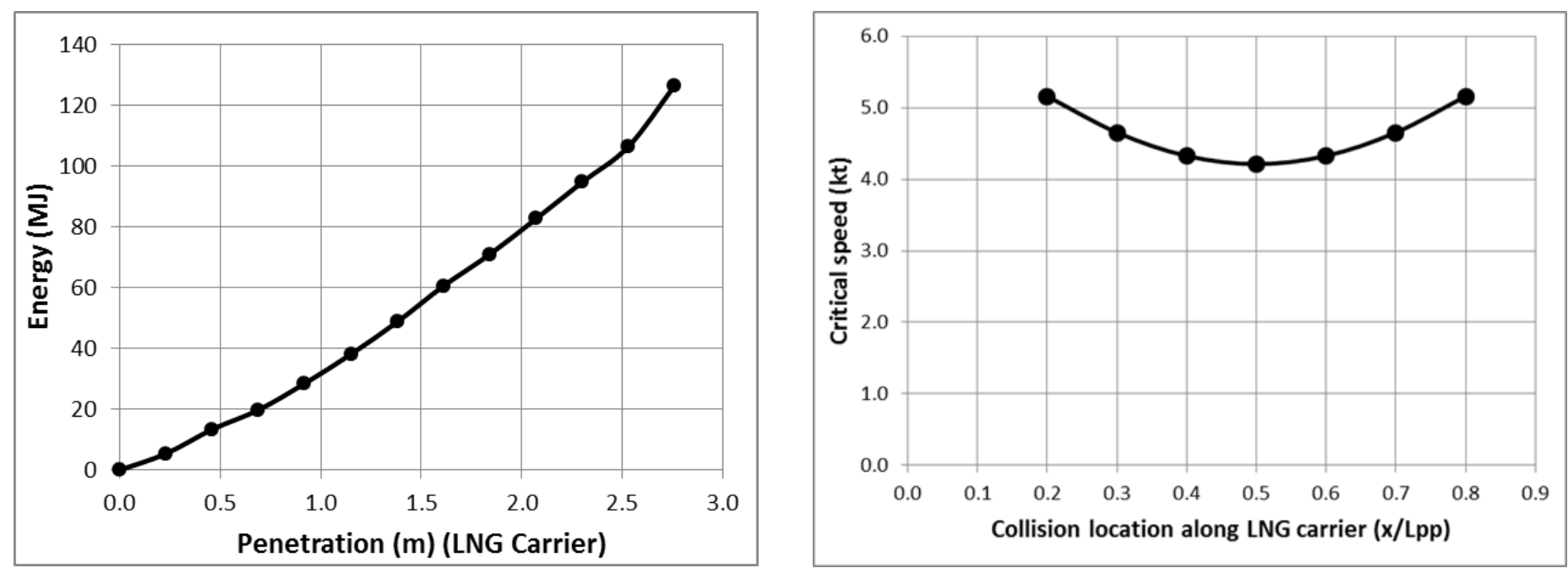

Figure 29: Energy-penetration curve and critical collision speeds along the ship length

\section{Conclusions}

The paper is dedicated to enhance the industry practice in collision assessments of ship structures when only limited time is available for the analysis. The idea is to establish a simple, but effective procedure to estimate the extent of the structural damage by determining the material volume of the damaged and ruptured structural members.

The predictions of the damaged material volume method have been compared with 18 experimental results and one full-scale collision accident, where the entire collision response is evaluated by means of the resulting energy-penetration and force-penetration curves. It is observed that the method gives consistently good agreement with all experiments evaluated here, and therefore, the method is recommended, with a high degree of confidence, for performing collision assessments of ship structures. The analytical method has already been recommended for the design appraisal of the LNG tank compartment of LNG-fuelled vessels [9].

Another practical application of the method has been demonstrated with the example in Section 6, where an analysis of a collision scenario which is of concern for the LNG energy industry is presented.

For future work, similar methods for grounding damage analysis [26] should be further developed and validated with a wide range of experimental data to establish an effective procedure to estimate grounding damage extent. Another important research topic is the failure criteria of materials, first discussed in [27] for ship collisions and grounding analysis and is worth further investigation to establish a unified robust criterion. 


\section{Acknowledgement}

The authors wish to thank Dr Sai Wong and colleagues at Lloyd's Register for their comments and supports. The views expressed in this paper are those of the authors and are not necessarily those of Lloyd's Register. The proposed analytical methods in the paper were originally developed when the first author working at Technical University of Denmark from June 1996 to March 1999.

The authors also wish to thank Dr Jörg Peschmann and Dr Ingo Martens for providing information on the related test models.

Lloyd's Register and variants of it are trading names of Lloyd's Register Group Limited, its subsidiaries and affiliates. Lloyd's Register EMEA (Reg. no. 29592R) is an Industrial and Provident Society registered in England and Wales. Registered office: 71 Fenchurch Street, London, EC3M 4BS, UK. A member of the Lloyd's Register group.

Lloyd's Register Group Limited, its affiliates and subsidiaries and their respective officers, employees or agents are, individually and collectively, referred to in this clause as the 'Lloyd's Register'. Lloyd's Register assumes no responsibility and shall not be liable to any person for any loss, damage or expense caused by reliance on the information or advice in this document or howsoever provided, unless that person has signed a contract with the relevant Lloyd's Register entity for the provision of this information or advice and in that case any responsibility or liability is exclusively on the terms and conditions set out in that contract

\section{References}

[1] Zhang S. The Mechanics of Ship Collisions. PhD thesis, Technical University of Denmark, Denmark, ISBN 87-89502-05-1, January 1999.

[2] Pedersen PT, Zhang S. Absorbed Energy in Ship Collisions and Grounding - Revising Minorsky's Empirical Method. Journal of Ship Research 2000: 44 (2): 140 - 154.

[3] Zhang S, Pedersen PT. A Method for Ship Collision Damage and Energy Absorption Analysis and Its Validation. Journal of Ship and Offshore Structures 2016; DOI: 10.1080/17445302.2016.1254584.

[4] Pedersen PT. Review and application of ship collision and grounding analysis procedures. Marine Structures 2010; 23 (3): 241 - 262.

[5] Zhang S, Villavicencio R, Zhu L, Pedersen PT. Impact mechanics of ship collisions and validations with experimental results. Journal of Marine Structures 2016; 52: 69 - 81.

[6] Amdahl J. Energy absorption in ship-platform impacts. PhD thesis, Department of Marine Technology, Norwegian University of Science and Technology, Trondheim, Norway 1983.

[7] Paik JK, Chung JY, Choe IH, Thayamballi AK, Pedersen PT, Wang G. On Rational Design of Double Hull Tanker Structures against Collision. The Society of Naval Architects and Marine Engineers Annual Meeting1999; SNAME. 107.

[8] Ehlers S. Material Relation to Assess the Crashworthiness of Ship Structures, Doctoral Dissertation, Helsinki University of Technology, Faculty of Engineering and Architecture, Department of Applied Mechanics 2009.

[9] Lloyd's Register. Guidance notes for collision assessment for the location of low-flashpoint fuel tanks; 2016.

[10] Minorsky VU. An Analysis of Ship Collision with Reference to Protection of Nuclear Power Ships, Journal of Ship Research 1959: 3 (2): 1-4.

[11] Ehlers S. The Influence of the Material Relation on the Accuracy of Collision Simulations. Marine Structures 2010: 23: 462-474.

[12] Martens I. Konstruktive Aspekte beim Entwurf von Bugwülsten zur Verbesserung des Energieaufnahmevermogens bei Schiffskollisionen. PhD Thesis; Schriftenreihe Schiffbau, Bericht 679. Germany: Technical University of Hamburg; 2014, ISBN 978-3-89220-679-8 (In German).

[13] Marinatos JN, Samuelides MS. Towards a Unified Methodology for the Simulation of Rupture in Collision and Grounding of Ships. Marine Structures 2015; 42: 1-32. 
[14] Storheim M, Amdahl J., Martens I. On the Accuracy of Fracture Estimation in Collision Analysis of Ship and Offshore Structures. Marine Structures 2015; 44: 254-287.

[15] Liu B, Villavicencio R, Zhang S, Guedes Soares C. A simple criterion to evaluate the rupture of materials in ship collision simulations. Marine Structures 2017; 54: 92-111.

[16] Karlsson UB, Ringsberg JW, Johnson E, Hoseini M, Ulfvarson A. Experimental and numerical investigation of bulb impact with a ship side-shell structure. Marine Technology 2009; 46 (1): 16-26.

[17] Arita K, Aoki G. Strength of ship bottom in grounding ( $1^{\text {st }}$ report) - An investigation into the case of a ship stranded on a rock. Journal of the Society of Naval Architecture of Japan 1985; 158: 359 - 367 (In Japanese).

[18] Hallquist JO. LS-DYNA Theory Manual. California, USA: Livermore Software Technology Corporation; 2006.

[19] Villavicencio R, Liu B, Guedes Soares C. Experimental and numerical analysis of a tanker side panel laterally punched by a knife edge indenter. Marine Structures 2014; 17: 173 - 202.

[20] Wang G, Arita K, Liu D. Behavior of a Double Hull in a Variety of Stranding or Collision Scenarios. Marine Structures 2000; 13: 147 - 187.

[21] Ito H, Kondo K, Yoshimura N, Kawashima M, Yamamoto S. A Simplified Method to Analyze the Strength of Double Hulled Structures in Collision. The Autumn meeting of the Society of Naval Architects of Japan 1984; 158: 420 - 434.

[22] Tautz I, Schöttelndreyer M, Lehmann E, Fricke W. Collision tests with rigid and deformable bulbous bows driven against double hull side structures. Collision and Grounding of Ships and Offshore Structures - Amdahl, Ehlers \& Leira (Eds) (C) 2013 Taylor \& Francis Group, London, ISBN 978-1-138-00059-9.

[23] Lehmann E, Peschmann J. Energy absorption by the steel structure of ships in the event of collisions. Marine Structures 2002; 15: 429 - 441.

[24] Peschmann J. Energy absorption computations of ship steel structures under collision and grounding, PhD thesis, Technical University of Hamburg, 2001 (In German).

[25] Pedersen PT, Zhang S. On impact mechanics in ship collisions. Marine Structures 1998; 11 (10): 429 449.

[26] Zhu L, James P, Zhang S. Statistics and damage assessment of ship grounding, Marine Structures 2002, 15(4), 515-530

[27] Zhu L, Atkins AG, Failure criteria for ship collision and grounding. $7^{\text {th }}$ International symposium on practical design of ships and mobile units (PRADS). Amsterdam, Elsevier 1998. 